\title{
ANÁLISIS DE LA PRODUCCIÓN CIENTÍFICA SOBRE LA PINTURA RUPESTRE POSPALEOLÍTICA EN ESPAÑA. ARTE LEVANTINO Y PINTURA ESQUEMÁTICA (1907-2010)
}

\author{
Miguel Ángel Mateo Saura* \\ Investigador arte prehistórico. Comunidad Autónoma de la Región de Murcia. \\ Isidoro Gil-Leiva** \\ Universidad de Murcia. Facultad de Comunicación y Documentación. \\ Antonio Pulgarín-Guerrero*** \\ Universidad de Extremadura. Facultad de Biblioteconomía y Documentación.
}

\begin{abstract}
Resumen: El arte rupestre constituye una de las áreas de estudio de la prehistoria más atractiva debido quizás al hermetismo que nos trasmite aún hoy. Tras un siglo de investigación sobre la pintura rupestre pospaleolítica en España, y cuando la producción científica supera los dos mil registros, se aborda desde parámetros bibliométricos, el análisis de esta producción durante el periodo 1907-2010. Partiendo de una base de datos propia en Access elaborada durante más de veinte años y que a fecha de 31 de marzo de 2011 contaba con 2186 registros bibliográficos se aplican técnicas bibliométricas para conocer la distribución temporal, el idioma usado, los estilos de arte rupestre, las tipologías documentales, las temáticas abordadas en los trabajos y el lugar de publicación de los mismos. La producción de documentos se sitúa por debajo de 21,02 trabajos/año hasta 1970, si bien, en los 104 años de investigación analizados, destacan por el elevado número de publicaciones los años 1999 con el 4,5\% y 2006 con el 5,1\%. En cuanto al idioma de los documentos se distribuyen así, castellano (88,1\%), catalán $(4,6 \%)$, francés (3,9\%), inglés (2\%); alemán (1\%) y otros idiomas (italiano, portugués o gallego) con el 0,32\%. El 35,4\% de la producción está dedicada al arte levantino, mientras que la pintura esquemática acapara el 34,8\%. En cuanto a la tipología documental, destaca el artículo científico con el 55,2\% seguido de comunicaciones a congresos (19,2\%), capítulos de libro (11,3\%), monografías $(9,8 \%)$, notas $(2,3 \%)$, tesis doctorales $(1 \%)$ y tesinas de licenciatura $(0,7 \%)$. Las temáticas predominantes tratadas son los yacimientos (34,5\%), la cronología (8,8\%), la iconografía (7,7\%) o la divulgación (5,1\%). El 90,6\% de la producción científica ha sido editada en España, destacando Zaragoza (13,4\%), Madrid (13,3\%), Valencia (9,2\%) y Murcia (9\%). Consideramos que la producción total es baja porque apenas sobrepasa 21 trabajos/año, si bien, en los últimos cincuenta años se alcanzaron tasas de crecimiento por encima del $5 \%$. Debido a que el español es una de las lenguas más hablada en el mundo, sería necesaria una mayor internacionalización de la investigación de la pintura rupestre pospaleolítica española superando el marcado localismo e igualmente, se hace necesaria una mayor internacionalización de las revistas españolas del sector.

Palabras clave: Bibliometría; producción científica; prehistoria; pintura rupestre; pintura pospaleolítica; arte levantino; pintura esquemática.
\end{abstract}

Title: ANALYSIS OF THE SCIENTIFIC LITERATURE OF THE POST-PALAEOLITHIC PAINTING IN SPAIN. LEVANTINE ART AND SCHEMATIC PAINTING (1907-2010).

Abstract: Cave art constitutes one of the areas of study of prehistory more attractive, perhaps because of the secrecy that still conveys. After a century of research on post-Paleolithic cave painting in Spain, and when the scientific production exceeds two thousand records, is addressed from bibliometric parameters, the analysis of this production over the period 1907-2010. Based on an own database in Microsoft Access, prepared for over twenty years and that the March 31, 2011 counted on 2186 bibliographic records, bibliometric techniques are used to determine the temporal distribution, the language used, the styles of cave art, the document types, the themes addressed in the works and the publication place. Document production is below 21,02 publications/year until 1970, although in the 104 years of research analyzed, highlights the years 1999 (with 4,5\%) and 2006 (with 5,1\%) for the large number of publications. Regarding the language of the documents are distributed as follows, Spanish (88,1\%), Catalan (4,6\%), French (3,9\%), English (2\%), German (1\%) and other languages (Italian, Portuguese or Galician) with $0,32 \%$. 35,4\% of production is dedicated to Levantine art, while schematic painting captures 34,8\%. Regarding the document type, the scientific article stands out with $55,2 \%$, followed by conference papers $(19,2 \%)$, book chapters $(11,3 \%)$, case studies $(9,8 \%)$, notes $(2,3 \%)$, doctoral thesis $(1 \%)$ and undergraduate dissertations $(0,7 \%)$. The predominant topics are sites (34,5\%), chronology $(8,8 \%)$, iconography $(7,7 \%)$, or scientific divulgation $(5,1 \%)$. $90,6 \%$ of scientific production has been published in Spain, highlighting Zaragoza (13,4\%), Madrid (13,3\%),

\footnotetext{
*mateosaura@regmurcia.com

**isgil@um.es

*** apulgue@alcazaba.unex.es
}

Recibido: 04-03-2014; 1ª versión: 21-05-2014; 2ª versión: 27-06-2014; aceptado: 22-07-2014.

SAURA MATEO, M.A.; GIL LEIVA, I. y PULGARÍN GUERRERO, A. Análisis de la producción científica sobre la pintura rupestre pospaleolítica en España. Arte levantino y pintura esquemática (1907-2010). Anales de Documentación, 2014, vol. 17, nº 2. Disponible en DOI: http://dx.doi.org/10.6018/analesdoc.17.2.193781 
Valencia (9,2\%) and Murcia (9\%). We consider that the total production is low because hardly exceeds 21 papers / year, although in the last fifty years growth rates were reached above 5\%. Because Spanish is one of the most spoken languages in the world, greater internationalization of research of the Spanish post-Palaeolithic cave painting would be necessary, overcoming marked localism in which has been involved, as opposed to current view that cave art is a universal phenomenon present in all five continents and diverse cultural and chronological settings. Also, greater internationalization of Spanish industry magazines and a greater interest in the prehistoric art in general.

Keywords: Bibliometrics; scientific production; prehistory; rock painting; post-Palaeolithic painting; levantine art; schematic painting.

\section{INTRODUCCIÓN.}

El arte rupestre constituye una de las áreas de estudio de la prehistoria más atractivas, auspiciado quizás por el marcado hermetismo que nos trasmite aún hoy, tras más de cien años de investigación. Si a finales del siglo XIX el principal foco de discusión era el de su autenticidad, cuestionada en tanto que se negaba al hombre prehistórico, apriorísticamente, la capacidad cognitiva y cultural para desarrollar manifestaciones plásticas tan extraordinarias como Altamira o Lascaux, ahora, que ya no discutimos su cronología prehistórica, seguimos navegando en un mar de dudas cuando nos planteamos cuestiones, por ejemplo de autoría cultural o de semiótica, sobre las que se han apostado teorías muy diversas, a veces enfrentadas, pero sobre las que estamos aún muy lejos de encontrar unanimidad.

La declaración de Patrimonio Mundial del Arte Rupestre del Arco Mediterráneo (1998) y, más recientemente, del Arte Paleolítico de las cuevas de la cornisa cantábrica (2008), salvo Altamira que ya lo era desde 1985, y todo lo que ello ha supuesto de divulgación del arte prehistórico mediante actuaciones diversas (exposiciones, conferencias, publicaciones, etc.), podría haber marcado un antes y un después tanto en lo que se refiere a la investigación científica como a la actitud general de la sociedad, que ahora tendría que verlo como algo cercano, accesible y de lo que puede disfrutar. En este último ámbito de actuación se pueden encuadrar diversas iniciativas que procuran ese acercamiento del arte prehistórico, entre ellas la apertura de centros de interpretación o el desarrollo de cursos y seminarios sobre el tema.

Otras veces, la popularidad que el arte rupestre prehistórico ha alcanzado en amplios sectores de la sociedad es tal que, ajenos a lo que supone su investigación científica pero conscientes de su poder como reclamo, ven en él una marca de interés (Guitián y De la Peña, 2007), un referente icónico útil para sus fines.

En este contexto, presentamos en este trabajo los resultados del análisis bibliométrico de la producción científica sobre la pintura rupestre pospaleolítica, realizado con el objetivo de evaluar el rendimiento de la actividad científica una vez que se ha superado un siglo de investigación y cuando dicha producción supera los dos mil registros bibliográficos.

Evaluar la ciencia se presenta actualmente como una necesidad inexcusable si se procura una óptima adecuación de los recursos destinados a la investigación, máxime si consideramos las evidentes conexiones existentes entre los avances de la actividad investigadora y el crecimiento económico y social (Moya et al., 2010). Analizar el tamaño, crecimiento y distribución de la bibliografía científica, y los procesos de generación, propagación y uso de la misma, nos proporcionarán información valiosa acerca de su impacto en la sociedad, y de los mecanismos de la propia investigación científica y la estructura y dinámica de los colectivos de investigadores (Sancho, 1990). Ello justifica sobradamente la realización de análisis que permitan un seguimiento de esa actividad científica, cuyos resultados influirán, seguramente, en la toma de decisiones de la política científica. Además, una consecuencia no menos importante de la evaluación de la ciencia es que la misma contribuye a ofrecer una imagen social de esa actividad investigadora, transmitiendo la idea de que lo aportado por ésta revierte, de forma variada, a la propia sociedad, justificando el uso de los recursos.

La publicación de los resultados de cualquier investigación constituye uno de los pilares fundamentales de la propia ciencia, hasta el punto de que, como decía D. J. S. Price, el acto de la creación en la investigación científica estaría incompleto sin la publicación, al ser ésta la que facilita el proceso conectivo, la evaluación y, llegado el caso, la aceptación de esa investigación y de sus resultados por parte de la comunidad científica. Aunque estos resultados pueden ser transmitidos por canales que no están sustentados por medios institucionalizados de intercambio científico (Tortosa, 1985; Montoro y Carbonell, 1989), como son los contactos personales en seminarios, la correspondencia epistolar entre autores o las reuniones informales, no cabe duda de que el más destacado es el bibliográfico, entendido en términos de bibliografía impresa (Moya et al., 2010). De todas formas, es frecuente que, antes o después, lo transmitido en alguno de esos otros canales informales acabe siendo también publicado en modo impreso. 
Si en el ámbito de las Ciencias Experimentales y Tecnológicas los estudios bibliométricos han gozado de un desarrollo notable, no podemos decir lo mismo cuando nos referimos a las Humanidades y Ciencias Sociales, sobre las que han sido pocos los análisis realizados, y excepcionales si nos referimos al área de la prehistoria y la arqueología.

Entre las causas que han llevado a esta situación se insiste en el hecho de que las bases de datos de información bibliográfica susceptibles de utilizar como fuente carecen de la homogeneidad e información necesaria para el desarrollo de este tipo de análisis. Además, las referencias bibliográficas, en general, suelen faltar a unas mínimas reglas de normalización, siendo demasiado frecuentes la omisión de alguno de los datos o las equivocaciones a la hora de reseñar los mismos (Rodríguez et al., 1997). A ello se une que el carácter localista de los estudios en Ciencias Sociales y la amplitud de los canales de publicación han contribuido a la dispersión de sus publicaciones (Rubio, 1999; Rodríguez y Abejón, 2010). Es ésta una característica particularmente significativa en la investigación del arte rupestre, cuya edición de resultados encuentra buen acomodo en muchas ocasiones en publicaciones de impacto bajo, ya sea porque su titularidad corresponde a entidades locales, entre ellas ayuntamientos, museos municipales, u organismos privados de ámbito de actuación muy limitado, o también porque estos vehículos de edición carecen de una mínima labor de difusión que vaya más allá de su restringida área geográfica de influencia. Por ello, no resulta extraño encontrar interesantes trabajos de investigación, e incluso la presentación de novedades, en esos espacios privativos, trabajos que, por su calidad, bien podrían haber sido publicados en revistas científicas de mayor impacto.

La mayor parte de los estudios bibliométricos publicados sobre prehistoria y arqueología han tenido como objeto de estudio, precisamente, a las propias publicaciones periódicas, en un interés general por parte de las entidades editoras por conocer su adecuación a los ítems de calidad y el eventual grado de difusión (Rodríguez et al., 1996). Es el caso de Trabajos de Prehistoria (Rodríguez et al., 1993), del Boletín de la Asociación de Amigos de la Arqueología (Rovira, 1994), de Cota Zero (Cruells, 1995), de Hispania Antiqva (Crespo, 1995), del Archivo Español de Arqueología (García del Toro et al., 1999; Mora, 2002) y de la Revista d’Arqueologia de Ponent (Armada, 2009).

Aún más escasas son las referencias que tenemos de análisis bibliométricos efectuados sobre temas arqueológicos específicos, pudiendo reseñar tan solo los realizados sobre arqueometría de materiales cerámicos (García Heras, 1997; Cordero et al., 2006), sobre la investigación hispano portuguesa de la prehistoria y la protohistoria (García Marín et al., 1997) o sobre el arte rupestre levantino (Cruz et al., 1999).

\section{MATERIAL Y MÉTODO.}

El material usado para la realización del estudio ha sido una base de datos en Microsoft Access con 2186 registros bibliográficos. Esta base de datos ha sido alimentada desde 1992 partiendo de la memoria de licenciatura presentada por Mateo Saura (1992) hasta el 31 de marzo de 2011, fecha en la que se ingresaron los últimos documentos. Aunque se ha realizado un trabajo minucioso y concienzudo para conseguir un corpus lo más completo y exhaustivo posible, somos conscientes de que por el hecho de que el análisis se apoye en una base de datos de elaboración propia, creada a partir de la consulta manual de documentos y del vaciado de distintas bases de datos parciales, por lo dilatado del período de análisis, que abarca más de cien años, y por las tipologías documentales incluidas, entre ellas tesis doctorales, tesis de licenciatura y monografías, han podido quedar fuera algunas referencias. Pudiera tratarse de trabajos editados en soportes con escasa visibilidad, por ser trabajos que no están recogidos en las propias bases de datos examinadas, por haber una deficiente correlación entre el contenido de los documentos y los descriptores de búsqueda empleados, por tratarse de documentos editados con posterioridad a la fecha en que cerramos el registro de documentos, o también, admitámoslo, por un error en la propia búsqueda manual de éstos. En todo caso, consideramos que el corpus bibliográfico recopilado es casi un fiel calco de la realidad de los documentos producidos sobre la materia y que el número de trabajos que eventualmente ha podido quedar fuera de nuestro sistema de gestión de datos siempre será reducido, de manera que su ausencia ni altera sensiblemente los datos en que basamos nuestro análisis ni modifica significativamente los resultados obtenidos.

Las fuentes de información consultadas periódicamente para la inclusión de registros en nuestro repertorio han sido la base de datos del ISBN para libros y monografías; la base de datos TESEO para tesis doctorales; la base de datos ISOC del CSIC para artículos científicos y comunicaciones a congresos; la base de datos Dialnet; la base de datos Web of knowledge; el fondo bibliográfico Corpus de Pintura Rupestre Levantina del Instituto de Historia del CSIC; el catálogo de la Biblioteca de Humanidades de la Universidad de Murcia; y el catálogo de la Biblioteca del Centro de Arte Rupestre de Moratalla (Murcia). De igual modo, la lectura continuada de artículos científicos sobre la materia objeto de estudio a lo largo de estas décadas y una especial atención al apartado de bibliografía de los mismos, fueron proporcionando un importante número de referencias para su incorporación a nuestra base de datos. 
Para la interrogación de los catálogos y las bases de datos nacionales e internacionales mencionadas se usó terminología propia del arte rupestre como "arte rupestre”, "pintura rupestre”, "arte levantino”, "pintura levantina”, “arte esquemático” o "pintura esquemática”. Estos términos fueron usados para recuperar documentos que estuvieran presentes en los campos Materia, Título, Resumen, e incluso cuando no se recuperaban documentos o eran pocos, se usaba también la opción de "Cualquier campo". Posteriormente, eran analizados los documentos recuperados y las referencias bibliográficas no disponibles en nuestra propia base de datos se iban incorporando. En la consulta de la base de datos Web of knowledge se emplearon los términos ya mencionados pero en inglés: "rock art”, rupestrian painting”, "levantine art”, "levantine painting”, "schematic art” y "schematic painting”.

De esta manera se conformó la colección mencionada de 2186 documentos sobre los que se ha trabajado, publicados entre 1907, año en que se editan los primeros estudios realizados bajo criterios científicos, y 2010, último año de recogida e inclusión de documentos que finalizó el 31 de marzo de 2011. La base de datos con dichos documentos puede ser consultada en $<$ http://webs.um.es/isgil/>.

Elaborada la base de datos con 2186 referencias bibliográficas, se procedió a aplicar una serie de indicadores bibliométricos. Considerando la naturaleza de las fuentes de datos y las limitaciones que nos imponen, nuestro trabajo se centra en el análisis de la producción científica a partir del recuento de las publicaciones a lo largo del periodo estudiado (evolución de la producción científica), lo que nos permitirá determinar el crecimiento de nuestra ciencia y su eventual ajuste a una ciencia moderna. Igualmente hemos analizado la producción, según el idioma utilizado en sus publicaciones, con objeto de contrastar las posibles diferencias de uso entre unos idiomas y otros. Otro indicador utilizado ha sido la tipología documental, indicativa del tipo de fuente utilizada en las publicaciones y característico de cada ciencia. Por último, se ha abordado la temática resultante del estudio, cómo indicador de la diversidad investigadora llevada a cabo (Price, 1971).

\section{RESULTADOS Y DISCUSIÓN.}

\subsection{Distribución temporal de la producción.}

Aunque las primeras referencias escritas sobre la pintura rupestre pospaleolítica de la Península Ibérica se remontan al último tercio del siglo XVIII, cuando A. Ponz (1778) menciona en su Viaje por España el canchal de las cabras blancas de Las Batuecas, no es realmente hasta la primera década del siglo XX cuando podemos fijar los inicios de la investigación científica de esta faceta de la prehistoria española.

Para el análisis de este volumen de trabajos utilizamos como marco temporal de referencia la década. Consideramos adecuado este periodo de tiempo porque contribuye a minimizar los efectos de los retrasos en la edición de las revistas de ciencias sociales y humanidades en las que generalmente tienen cabida los trabajos dedicados al arte prehistórico. Aunque no es un hecho exclusivo de este ámbito de la ciencia, suele ocurrir con demasiada frecuencia que las revistas incumplan por motivos muy variados la periodicidad que ellas mismas recogen en sus normas de publicación, hasta el punto de que, en no pocas ocasiones y con el fin de actualizar la edición de números atrasados, se llega a editar un único volumen que reúne en un mismo año los trabajos producidos en dos o más años distintos. Con este problema, computar la producción científica por año de edición desvirtuaría, sin duda, el proceso de investigación, que no podría ser valorado en tiempo real.

Asimismo, si tanto en el ámbito de las Ciencias Experimentales como en el de las Humanidades se suele estimar que transcurren como media dos años desde el inicio de las investigaciones hasta que se publican sus conclusiones (Maltrás, 2003), cuando nos referimos al estudio y publicación de resultados sobre arte rupestre prehistórico este periodo de tiempo suele ser más amplio. Desde que se descubre un nuevo yacimiento hasta que se publican los datos de su estudio pueden llegar a pasar de tres a cinco años, obligados por variables tan dispares como puedan ser la obtención de financiación para la realización del estudio, la adopción de medidas preventivas de conservación previas al desarrollo del mismo, las dificultades de índole técnica que presenten las propias manifestaciones gráficas o el acomodo de la propia publicación en un formato y contexto bibliográfico adecuado. Por este motivo consideramos también que el empleo de la década como unidad temporal de análisis contribuye a minimizar esos mismos efectos negativos.

Desde la primera década de la investigación, en la que salen editados un total de 13 trabajos, y durante los primeros cincuenta años de estudio la producción bibliográfica presenta leves altibajos (Tabla I). Sí es cierto que durante la segunda década de trabajo la producción prácticamente triplica la muestra inicial, auspiciado ello, sin duda, por la proliferación de los descubrimientos. En ello intervienen activamente instituciones muy variadas, con especial protagonismo de algunas asociaciones excursionistas y, sobre todo, del Instituto de Paleontología Humana de París y 
de la Comisión de Investigaciones Paleontológicas y Prehistóricas de Madrid. Las tres décadas siguientes, de 1921 a 1959, van a ser de estancamiento e incluso de retroceso en la edición de documentos. Muy negativa va a ser la década de los años treinta, marcada por la Guerra Civil, en la que tan sólo se editan 17 trabajos. De éstos, 10 son anteriores a 1935 y de los siete restantes, cuatro están firmados por H. Obermaier, quien tras el estallido de la contienda bélica opta por el exilio.

\begin{tabular}{|c|c|c|c|c|c|c|}
\hline Década & $\begin{array}{c}\text { Total de } \\
\text { Publicaciones }\end{array}$ & $\%$ & $\begin{array}{l}\% \\
\text { acum. }\end{array}$ & Artículos & $\%$ & $\begin{array}{l}\% \\
\text { acum. }\end{array}$ \\
\hline No consta & 3 & 0,1 & & & & \\
\hline $1901 / 1910$ & 13 & 0,6 & 0,5 & 12 & 1 & 1 \\
\hline $1911 / 1920$ & 40 & 1,8 & 2,4 & 27 & 2,2 & 4,2 \\
\hline $1921 / 1930$ & 38 & 1,7 & 4,1 & 30 & 2,4 & 6,7 \\
\hline $1931 / 1940$ & 17 & 0,7 & 4,9 & 10 & 0,8 & 7,5 \\
\hline $1941 / 1950$ & 39 & 1,8 & 6,7 & 24 & 1,9 & 9,5 \\
\hline $1951 / 1960$ & 69 & 3,1 & 9,9 & 43 & 3,5 & 13 \\
\hline $1961 / 1970$ & 119 & 5,5 & 15,3 & 60 & 4,9 & 18 \\
\hline $1971 / 1980$ & 196 & 8,9 & 24,3 & 128 & 10,6 & 28,6 \\
\hline $1981 / 1990$ & 463 & 21,1 & 45,4 & 258 & 21,3 & 49,3 \\
\hline $1991 / 2000$ & 549 & 25,1 & 70,6 & 319 & 26,4 & 76,3 \\
\hline $2001 / 2010$ & 640 & 29,2 & 100 & 297 & 24,5 & 100 \\
\hline
\end{tabular}

Tabla I. Distribución de la producción por décadas.

En la década de los cuarenta, la estabilización paulatina de los estudios universitarios, y la labor desarrollada desde el extranjero por investigadores exiliados permite recuperar los índices de producción del periodo anterior a la Guerra Civil, siendo ya en la década siguiente cuando casi se duplica la producción. Pero es a partir de los años sesenta cuando ésta experimenta un progresivo incremento que nos permite decir que, a partir de este momento, la producción científica se ajusta al modelo de crecimiento exponencial postulado por D. J. S. Price (1961).

Sin duda, contribuye en gran medida al despegue de la producción bibliográfica el que los autores que van a dominar, prácticamente, las dos décadas siguientes ocupen las cátedras de prehistoria o arqueología de alguna de las universidades más activas. Es el caso de A. Beltrán Martínez en la Cátedra de Arqueología, Numismática y Epigrafía de la Universidad de Zaragoza; de F. Jordá Cerdá, en la Cátedra de Arqueología en la Universidad de Salamanca; de E. Ripoll Perelló, en el Área de Prehistoria de la Universidad de Barcelona, luego de Oviedo y finalmente de la UNED en Madrid; de M. Almagro Basch, primero en la Universidad de Barcelona y después en la Cátedra de Historia del Hombre de la Universidad de Madrid; o de P. Acosta Martínez, primero como ayudante en el Departamento de Arqueología de la Universidad de la Laguna y luego desde la Cátedra de Prehistoria de la Universidad de Sevilla.

En las últimas décadas, la producción ha crecido de manera considerable, sobre todo por la incorporación a la investigación de un amplio grupo de autores, consecuencia de la generalización de los estudios arqueológicos en la universidad española, y por una mayor implicación de las distintas administraciones, sobre todo tras la declaración por la UNESCO del Arte Rupestre del Arco Mediterráneo como Patrimonio Mundial.

Si hacemos un análisis de la producción de artículos científicos, menos sujetos a la eventualidad que padecen otros formatos de edición, como son las comunicaciones a congresos o las monografías, podremos cotejar los datos obtenidos con los resultados referentes al total de la producción. En este caso, los datos muestran, en general, la misma tendencia hacia un progresivo aumento de la producción de los artículos, que discurre de forma paralela a la de la producción global. Durante las tres primeras décadas de investigación hay un incremento importante de la producción de artículos, cierto que es mínimo entre la segunda y la tercera, para sufrir un destacado retroceso en los años treinta como consecuencia de la Guerra Civil de 1936. Tras una leve recuperación en los años cuarenta, será a partir de entonces cuando inicie un despegue, con tasas de crecimiento positivas, excepto en la última década de investigación en la que el número de artículos disminuye levemente.

Valorada en su globalidad, la producción de documentos se sitúa por debajo de la media de 21,02 trabajos/año hasta 1970, manteniéndose con algunos altibajos a lo largo de la década siguiente. Es a partir de los años ochenta cuando se supera de forma clara esa media, duplicándose prácticamente desde entonces cada año. De hecho, la media de producción de los últimos treinta años es de 50,13 publicaciones/año. De entre los 104 años de investigación analizados, destacan por el elevado número de publicaciones los años 1999, con 99 trabajos editados, y 2006 con 113 , que suponen el 4,5\% y el 5,1\%, respectivamente, del total de la producción. 


\subsection{Distribución de la producción por idioma.}

Atendiendo al indicador del idioma, el número total de documentos es de 2189 ya que tres de ellos han sido objeto de una edición bilingüe, dos en castellano-catalán y uno en inglés-francés. El castellano es el idioma de edición elegido mayoritariamente, con 1927 trabajos sobre el total, lo que supone el 88.1\% de la producción (Tabla II). Tan sólo en la primera década de la investigación el castellano se ve superado por el francés, con seis trabajos, y por el catalán, con cuatro, lo que se explica porque, por entonces, la investigación del arte prehistórico español estaba en manos de miembros del Instituto de Paleontología Humana de París, con el abate H. Breuil al frente, y por miembros de diversas instituciones catalanas como el Institut d'Estudis Catalans y el Centre Excursionista de Catalunya, con investigadores como C. Rocafort o L. M. Vidal.

\begin{tabular}{|c|c|c|c|c|c|c|c|c|c|c|c|c|c|}
\hline $\begin{array}{l}\text { Década/ } \\
\text { Idioma }\end{array}$ & $\begin{array}{l}1901 \\
/ 10\end{array}$ & $\begin{array}{l}11 \\
/ 20\end{array}$ & $\begin{array}{l}21 \\
/ 30\end{array}$ & $\begin{array}{l}31 \\
140\end{array}$ & $\begin{array}{l}41 \\
/ 50 \\
\end{array}$ & $\begin{array}{l}51 \\
/ 60\end{array}$ & $\begin{array}{l}61 \\
/ 70 \\
\end{array}$ & $\begin{array}{l}71 \\
/ 80 \\
\end{array}$ & $\begin{array}{l}81 \\
/ 90 \\
\end{array}$ & $\begin{array}{l}91 \\
/ 00 \\
\end{array}$ & $\begin{array}{l}2001 \\
/ 10\end{array}$ & $\mathbf{s} / \mathbf{f}$ & Total \\
\hline Castellano & 3 & 30 & 21 & 11 & 35 & 54 & 100 & 173 & 413 & 506 & 580 & 1 & 1.927 \\
\hline Catalán & 4 & 0 & 5 & 1 & 1 & 0 & 1 & 8 & 26 & 26 & 29 & - & 101 \\
\hline Francés & 6 & 10 & 6 & 3 & 1 & 8 & 15 & 3 & 16 & 6 & 11 & 1 & 86 \\
\hline Inglés & 0 & 0 & 2 & 0 & 1 & 0 & 1 & 9 & 2 & 10 & 20 & - & 45 \\
\hline Alemán & 0 & 0 & 4 & 2 & 1 & 7 & 2 & 3 & 3 & 0 & 0 & 1 & 23 \\
\hline Italiano & 0 & 0 & 0 & 0 & 0 & 0 & 0 & 0 & 4 & 0 & 0 & - & 4 \\
\hline Portugués & 0 & 0 & 0 & 0 & 0 & 0 & 0 & 0 & 1 & 0 & 1 & - & 2 \\
\hline Gallego & 0 & 0 & 0 & 0 & 0 & 0 & 0 & 0 & 0 & 1 & 0 & - & 1 \\
\hline Totales & 13 & 40 & 38 & 17 & 39 & 69 & 119 & 196 & 465 & 549 & 641 & 3 & 2.189 \\
\hline
\end{tabular}

Tabla II. Distribución de la producción científica por idioma.

De hecho, dos de los tres trabajos publicados en castellano durante esta primera década tienen cabida en publicaciones de estas instituciones catalanas, y una de ellas está firmada por autores que también han publicado en catalán, los citados Rocafort y Vidal.

A partir de este momento, el castellano se impone claramente como idioma principal de edición, aunque algunos autores extranjeros sigan trabajando sobre el tema en años posteriores, de ahí que, entre estos, el francés siga teniendo un peso importante hasta 1920, con un 25\% del total de trabajos editados en ese periodo.

Después del castellano, el catalán es el segundo idioma más utilizado, con 101 trabajos, lo que supone el 4,6\% sobre el total. El 80,2\% de la producción en catalán se ha editado en los últimos treinta años, ya que hasta 1981 tan sólo se habían publicado 20 documentos, nueve de ellos antes de 1930. Las circunstancias políticas derivadas del régimen establecido tras la Guerra Civil de 1936 explican la práctica desaparición del catalán, así como su posterior irrupción a partir de los años ochenta, con la instauración nuevamente del régimen constitucional. Entre 1982 y 2010 se publican 71 trabajos en catalán, lo que supone el 4,3\% del total de documentos publicados en ese tiempo. En cualquier caso, no es posible diferenciar un grupo de autores que escriban exclusivamente en catalán, ya que lo hacen indistintamente en este idioma y también en castellano. La elección de uno u otro viene determinada por la procedencia de la publicación en la que se incluye el documento.

Tras los primeros años de investigación, el francés irá perdiendo protagonismo, quedando con unos índices bajos sobre el total de la producción puesto que si bien investigadores pioneros como H. Breuil o H. Obermaier seguirán publicando, prácticamente, hasta mediados del siglo pasado, lo harán en menor cuantía y periodicidad. Es cierto que a ellos se suman los trabajos firmados por algún autor español que había optado por el exilio tras la Guerra Civil, como P. Bosch, y también los de aquellos otros que, adscritos a universidades españolas, se animan a publicar en revistas francesas como L’Anthropologie o el Bulletín de la Société Préhistorique Française.

En la segunda mitad del siglo XX y primera década del XXI, el francés seguirá estando presente, aunque con un índice de representatividad cada vez menor. Así, los valores más destacados los alcanza en la década de los sesenta, con un total de 15 trabajos (12,6\%) sobre los 119 de todo el periodo. En ello tiene gran incidencia la celebración de sendos congresos internacionales en los que el arte prehistórico español está presente, como son el Encuentro de Wartenstein de 1960 y el Simposio de Valcamónica de 1968. Las últimas décadas presentan cifras muy modestas, con un 3,4\% de todo lo publicado en la de 1981-1990, y un 1,7\% en la de 2001-2010.

El inglés tiene poca presencia durante los primeros noventa años de la investigación, periodo en el que tan sólo se publican 16 trabajos en este idioma. Sobresale, en este tiempo, la década de 1971 a 1980, en la que se editan nueve 
trabajos, lo que supone el 4,9\% del total de documentos editados en ese tiempo. Pero, de esos nueve trabajos, cinco están firmados por un mismo autor, M. J. Walker, antropólogo británico que por entonces llega a Murcia para realizar diversas investigaciones entre las que el arte levantino es un campo de estudio más. Las razones de la escasa presencia del inglés en la producción científica es doble, se debe en primer lugar, a que posiblemente, la escuela imperante en la investigación prehistórica es la francesa y, en segundo lugar, a que la enseñanza del inglés en la educación española no comienza a implantarse hasta la década de 1980.

En los dos últimos decenios de la investigación, el inglés ha recuperado cierto protagonismo, siempre dentro de la modestia que presentan los idiomas extranjeros en relación a la producción en castellano. Así, entre 1991 y 2010 se han publicado 30 documentos, lo que constituye el 2,5\% del global de documentos del periodo, merced a la labor de algún investigador español que trabaja en organismos extranjeros, de investigadores extranjeros que se interesan por el arte rupestre español, por la voluntad de unos pocos autores españoles movidos por la difusión internacional de su trabajos y por los cambios normativos ministeriales introducidos en los últimos años que afectan a la carrera profesional y curricular de los profesores universitarios españoles.

El alemán tiene una presencia prácticamente testimonial, con un grupo de 23 trabajos publicados, lo que supone el 1\% de toda la producción. Su aparición en la investigación es temprana, dada la presencia de H. Obermaier, investigador alemán adscrito en un primer momento al Instituto de Paleontología Humana de París, posteriormente a la Comisión de Investigaciones Prehistóricas y Paleontológicas del Museo de Ciencias Naturales de Madrid y, desde 1922, a la primera cátedra de prehistoria de una universidad española, también en Madrid. Suyos serán los primeros trabajos publicados en este idioma antes de la década de los años cuarenta, junto a los firmados por otro investigador alemán, H. Kühn. Entre 1951 y 1960 es cuando se publican hasta siete trabajos, lo que representa el 10,1\% sobre el total de este periodo.

Otros idiomas tienen una presencia casi anecdótica. Es el caso del italiano, representado con cuatro trabajos publicados en la década de 1981-1990; el portugués, con dos trabajos editados en 1990 y 2001; y el gallego, del que tan sólo hemos recogido un documento fechado en 1998.

\subsection{Distribución de la producción por estilo: levantino vs esquemático.}

Los datos generales obtenidos indican que los dos estilos han sido estudiados en unos porcentajes muy similares. Al margen de los 648 documentos (29,8\%) que hemos englobado en un grupo denominado 'General' en el que se incluyen los trabajos que tratan, bien de la pintura rupestre pospaleolítica en conjunto o también que se centran en el estudio de alguno de los apartados temáticos sin ceñirse a un estilo en concreto, los documentos dedicados al análisis del arte levantino o a alguno de sus aspectos son 776, lo que constituye el 35.4\% de la producción, mientras que sobre la pintura esquemática los trabajos editados son 762, el 34,8\% (Tabla III).

\begin{tabular}{cccccccccc}
\hline $\begin{array}{c}\text { Década/ } \\
\text { Estilo }\end{array}$ & $\begin{array}{c}\text { Arte } \\
\text { Levantino }\end{array}$ & $\begin{array}{c}\mathbf{\%} \\
\text { estilo }\end{array}$ & $\begin{array}{c}\text { \% } \\
\text { total }\end{array}$ & $\begin{array}{c}\text { Pintura } \\
\text { Esquemática }\end{array}$ & $\begin{array}{c}\text { \% } \\
\text { estilo }\end{array}$ & $\begin{array}{c}\text { \% } \\
\text { total }\end{array}$ & $\begin{array}{c}\text { Temática } \\
\text { General }\end{array}$ & $\begin{array}{c}\% \\
\text { estilo }\end{array}$ & $\begin{array}{c}\text { \% } \\
\text { total }\end{array}$ \\
\hline $1901-10$ & 11 & 1,4 & 0,5 & 2 & 0,2 & 1 & 0 & - & - \\
\hline $1911-20$ & 22 & 2,8 & 1 & 11 & 1,4 & 0,5 & 7 & 1,1 & 0,3 \\
\hline $1921-30$ & 20 & 2,5 & 0,9 & 9 & 0,4 & 8 & 1,2 & 0,3 \\
\hline $1931-40$ & 12 & 1,5 & 0,5 & 2 & 0,2 & 1 & 3 & 0,4 & 0,1 \\
\hline $1941-50$ & 25 & 3,2 & 1,1 & 9 & 1,1 & 0,4 & 5 & 0,7 & 0,2 \\
\hline $1951-60$ & 40 & 5,1 & 1,8 & 13 & 1,7 & 0,6 & 16 & 2,4 & 0,7 \\
\hline $1961-70$ & 61 & 7,8 & 2,8 & 31 & 4,1 & 1,4 & 26 & 4 & 1,1 \\
\hline $1971-80$ & 75 & 9,6 & 3,4 & 93 & 12,2 & 4,2 & 28 & 4,3 & 1,2 \\
\hline $1981-90$ & 125 & 16,1 & 5,7 & 201 & 26,3 & 9,2 & 135 & 20,8 & 6,1 \\
\hline $1991-00$ & 156 & 20,1 & 7,1 & 217 & 28,4 & 9,9 & 178 & 27,4 & 8,1 \\
\hline $2001-10$ & 229 & 29,5 & 10,4 & 174 & 22,8 & 7,9 & 242 & 37,3 & 11 \\
\hline Totales & 776 & & 35,4 & 762 & & 34,8 & 648 & & 29,6 \\
\hline
\end{tabular}

Tabla III. Distribución de la producción científica por estilos.

Si analizamos la evolución de la producción por estilos y por décadas, las cifras sí arrojan ciertas variaciones en el modo en que cada uno de esos estilos ha sido objeto de estudio y publicación. Desde los inicios de la investigación el número de documentos que tienen al estilo levantino como objeto de estudio es superior al referido a la pintura 
esquemática y hasta la década de los setenta los trabajos editados sobre el horizonte levantino duplican en número a los referidos al estilo esquemático, llegando a triplicarla, incluso, durante los años cincuenta. Es a partir de los años ochenta cuando se invierte la situación. Entre las causas que explicarían esta circunstancia sobresale el protagonismo que desde los inicios de la propia investigación adquiere el estilo levantino por lo llamativo de su lenguaje figurativo, que hace que las representaciones esquemáticas, de factura aparentemente más torpe, con un lenguaje, por el contrario, abstracto y, a priori, menos narrativo, quedase como un arte menor dentro del fenómeno gráfico prehistórico. Asimismo, la notable diversidad de formas advertidas dentro de lo que se conoce como arte esquemático lo convertía en una especie de cajón de sastre en el que tenía cabida todo aquello que no fuera, o pareciera, ni paleolítico ni levantino, lo que a su vez se traducía en cierto desinterés por su estudio dada su aparente heterogeneidad.

La edición de la tesis doctoral de P. Acosta en 1968 sobre La pintura rupestre esquemática en España constituye un punto de inflexión en la investigación de la pintura rupestre de estilo esquemático. Su elaboración supone la primera sistematización de este horizonte gráfico, y sienta las bases sobre las que edificar los estudios futuros. En esta reafirmación de lo esquemático, la celebración en 1982 en Salamanca del Coloquio Internacional sobre Arte Esquemático viene a significar su reconocimiento definitivo como horizonte cultural y estético al modo en que lo estaban, desde hacía mucho tiempo, los estilos paleolítico y levantino, adquiriendo definitivamente carta de naturaleza por sí mismo.

En esta línea de estudio del estilo esquemático se enmarcan también las dos ediciones del Congreso sobre Arte Rupestre Esquemático en la Península Ibérica, celebradas en Almería en 2004 y 2010, que vienen a ratificar la identidad propia de lo esquemático como horizonte gráfico dentro de la prehistoria peninsular.

\subsection{Distribución de la producción por el tipo de documento.}

El tipo de documento mayoritariamente elegido para la publicación de resultados de las investigaciones es el artículo científico, con 1208 documentos, el 55,2\% sobre el total de la producción. Unos porcentajes menores muestran las comunicaciones a congresos, 421 (19,2\%), los capítulos de obras colectivas, 248 (11,3\%) o las monografías, 218 (9,8\%). Las tesis doctorales son 23 (1\%) y las tesinas de licenciatura 16 (0,7\%). Un último grupo de documentos son las notas, de las que tenemos 52 ejemplos (2,3\%) (Figura 1).

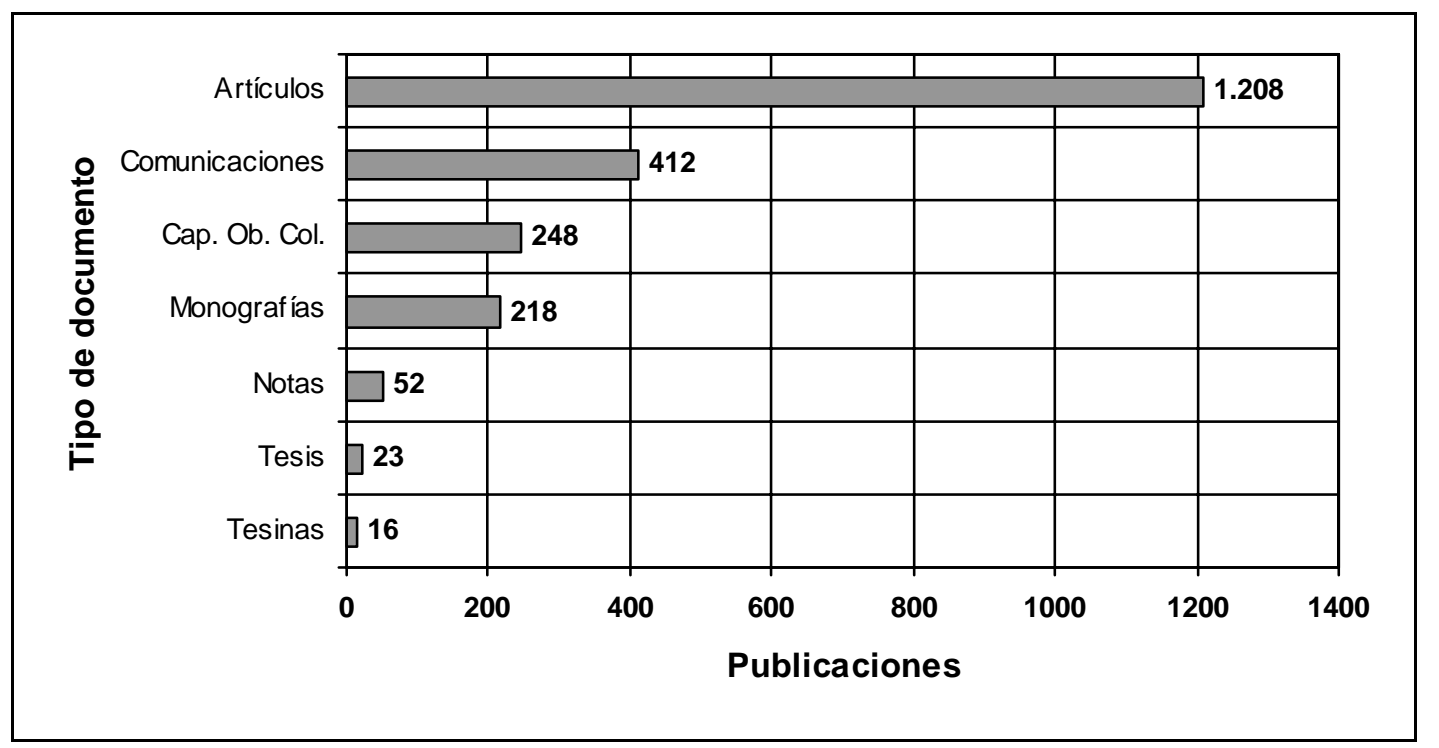

Figura 1. Distribución de la producción científica por tipologías documentales.

De entrada, estos datos sitúan nuestra disciplina en consonancia con el panorama predominante en el ámbito de las Ciencias Experimentales, en las que el artículo científico es el formato de edición mayoritario. Esto contradice el postulado generalmente aceptado de que en el ámbito de las Ciencias Sociales y Humanidades tanto el libro como las comunicaciones a congresos tienen mayor presencia e importancia que los artículos científicos, sobre todo en el campo de la Historia (Rubio, 1999), lo que estaría, a priori, justificado por la baja obsolescencia de estas disciplinas y porque la tradición historiográfica valora científicamente en mayor medida el libro.

Las comunicaciones a congresos han estado presentes desde antiguo. La primera referencia a la pintura rupestre pospaleolítica en un congreso se retrotrae a 1915, al congreso organizado en Valladolid por la Asociación Española 
para el Progreso de las Ciencias. Cinco años más tarde encontramos también una reseña en las actas del II Congreso de Historia de la Corona de Aragón, y desde 1947 el tema va a estar presente, prácticamente, en todas las ediciones de los Congresos Nacionales de Arqueología, si bien con un carácter testimonial en la mayoría de ellos, a excepción de las ediciones de Castellón en 1987, de Teruel en 1991 y de Cartagena en 1997, en las que se presentó un mayor número de comunicaciones, 18, 10 y 18 , respectivamente.

También es temprana la fecha en la que las comunicaciones sobre pintura rupestre pospaleolítica peninsular superan las fronteras nacionales. En 1939, H. Obermaier presenta una comunicación al congreso organizado por el Museo de Toulouse en homenaje al conde H. Begoüen, aunque los dos encuentros más destacados van a ser los celebrados en Wartenstein en 1960 y en Valcamónica en 1968. Si bien es cierto que las aportaciones españolas en estos congresos no fueron numéricamente muy destacadas, con siete y cuatro comunicaciones respectivamente, el verdadero interés de las mismas es que, al presentarse en foros de debate extranjeros, suponían un cierto grado de internacionalización del tema y una primera contextualización de los horizontes peninsulares levantino y esquemático dentro de un fenómeno universal como es el del arte prehistórico.

La declaración como Patrimonio Mundial del Arte Rupestre del Arco Mediterráneo en 1998 fue el desencadenante para la dedicación de varios congresos al tema. Es el caso de los encuentros sobre Arte Rupestre en la España Mediterránea (Alicante, 2005), sobre Arte Rupestre Esquemático de la Península Ibérica (Almería, 2006) o sobre El Arte Rupestre del Arco Mediterráneo de la Península Ibérica (Valencia, 2008), cuyas comunicaciones, 85 en total, han supuesto el 48,2\% de las producidas en la década 2001-2010. A éstos habría que añadir otros seminarios de los que, a día de hoy, todavía no se han publicado las actas, como los celebrados en Barcelona en 2009 sobre La Datación del Arte Rupestre Mediterráneo Peninsular, en Murcia en 2010 sobre La Documentación Gráfica del Arte Rupestre, o en Almería también en 2010 acerca del Arte Esquemático en la Península Ibérica, y cuyas aportaciones, al permanecer todavía inéditas, no han podido ser contabilizadas en nuestro estudio.

Si el análisis de las tesis doctorales y de las tesinas permite conocer qué universidades, facultades o departamentos son los más productivos y cuáles son sus líneas de investigación (Rubio, 1999), convendremos que el moderado número tanto de tesis doctorales como de memorias de licenciatura con que contamos, 23 y 16 respectivamente, puede ser indicio más que fiable de la limitada atención que la universidad española, en general, ha prestado al estudio de la pintura rupestre pospaleolítica. En todo caso debemos reseñar que 20 de las 23 tesis doctorales se han defendido en los últimos veinte años, lo que supone el 86,9\% del total del grupo, lo que podría ser interpretado como un síntoma de que esta realidad estaría cambiando paulatinamente.

Sí se percibe una cierta sensibilidad hacia el tema por parte de aquellos centros situados en territorios que cuentan con un importante número de yacimientos con arte rupestre, aunque también en este punto hay detalles que llaman la atención. Así, universidades como las de Alicante y la de Valencia, cuyos territorios cuentan con un destacado número de conjuntos levantinos y esquemáticos, reúnen cuatro tesis doctorales cada una de ellas, a las que hay se sumar otras dos tesis más defendidas en la Universidad Politécnica de Valencia. Por el contrario, la Universidad de Murcia, provincia que aglutina más de 100 yacimientos, sólo cuenta con una tesis doctoral, presentada además en la Facultad de Biología y no, como cabría esperar, en la de Geografía e Historia.

Mientras, la Facultad de Geografía e Historia de la Universidad Nacional de Educación a Distancia, en Madrid, cuenta con otras cuatro tesis doctorales, si bien es cierto que la propia idiosincrasia de esta institución académica no implica una identificación tan estrecha entre territorio e institución respecto del objeto estudiado. Es así que las cuatro tesis doctorales realizadas han tenido como tema de estudio el arte pospaleolítico de áreas tan alejadas como Cádiz, Cuenca, Badajoz y Málaga.

Un panorama muy próximo al descrito por las tesis doctorales es el que se desprende del análisis de las memorias de licenciatura. Con tan sólo 16 ejemplos, la producción se concentra entre los años 1970 y 2000. Llama la atención que en la última década, tras la declaración del arte rupestre levantino como patrimonio mundial en 1998, no se haya presentado ninguna nueva tesis de licenciatura sobre el tema, lo que podría indicar que tal declaración, que en el ámbito de la administración sí ha supuesto la adopción de medidas de conservación, divulgación y puesta en valor del arte rupestre, no ha tenido apreciables consecuencias dentro del ámbito académico.

Las notas son 52, lo que supone el 2,3\% del total de documentos. A pesar de su reducido número, han estado presentes desde los comienzos de la investigación, lo que se justifica en parte por las propias características del documento que lo ha convertido, con frecuencia, en vehículo de avance de los descubrimientos. Desde los años cuarenta hasta los ochenta, el número de notas por década se situaba en torno a las cinco, adquiriendo un notable 
incremento en el periodo 1991-2000, en el que registramos 12, el 23\% de su producción total. En esta última década de investigación su número ha descendido al 5,7\%, con tan sólo tres documentos.

Los datos obtenidos en nuestro análisis sobre el formato de edición coinciden, en general, con los ofrecidos por los análisis bibliométricos efectuados sobre otras materias arqueológicas. En la investigación realizada sobre materiales cerámicos arqueológicos en España (García Heras, 1997), basada en una muestra de 262 trabajos editados entre 1972 y 1995, el tipo de soporte de edición mayoritario era también el artículo, con el 41,7\% del total de la producción. En segundo lugar se encontraban las comunicaciones a congresos, con el 31,8\%, y en tercer lugar, las monografías, con el 17,4\%. Las tesis doctorales y las tesinas, recogidas también en ese estudio, suponían el 4,9\% y el 4\%, respectivamente, del global de la producción, porcentajes que sí son sensiblemente superiores a los definidos por nosotros. Ello revelaría, quizás, una mayor implicación del estudio de los materiales cerámicos en el ámbito universitario y, evidentemente, un mayor interés por su investigación en los estudios de posgrado.

Este mismo tema de análisis fue abordado años después, aunque circunscrito esta vez a los materiales cerámicos arqueológicos de Andalucía, en una muestra creemos que demasiado reducida como para extraer conclusiones generales, apenas 59 publicaciones, editadas entre los años 1979 y 2002 (Cordero et al., 2006). En todo caso, el artículo sigue siendo el tipo de documento mayoritario, con el 37\%, pero las monografías ocupan el segundo lugar con el 37,5\%, superando a las comunicaciones a congresos, que representan el 22,5\%.

Por su parte, en un análisis bibliométrico efectuado sobre una muestra de 521 registros publicados antes de 1997 sobre el arte rupestre levantino (Cruz et al., 1999), los artículos constituyen el grupo de documentos más numeroso, con el 56,4\%, seguidos por las comunicaciones a congresos, con el 17,1\% y las notas, con el 12,1\%. Le siguen, por orden decreciente, las monografías con el 6,5\%, los capítulos de libro con el 5,2\%, los libros con el 2,3\% y las recensiones con el $0,2 \%$.

\subsection{Distribución de la producción por temática.}

De acuerdo con los contenidos generalmente tratados en los estudios sobre la pintura rupestre pospaleolítica, hemos definido once categorías temáticas diferentes. Estas han sido establecidas a partir de los términos empleados en el título de los trabajos, en los resúmenes de los mismos y de las palabras clave aportadas. Asimismo, hemos procurado mantener, en la medida de lo posible, la homogeneidad con el estudio bibliométrico efectuado hace unos años sobre el arte rupestre levantino (Cruz et al., 1999) con el fin de facilitar el contraste de los datos. No obstante, nosotros hemos creído conveniente individualizar alguno de los bloques temáticos tratados entonces de forma conjunta, como es el caso de 'Conservación-Metodología', a la vez que hemos incorporado otros de reciente aparición como el de 'Gestión’. A ellas hemos ido adscribiendo los documentos, lo que nos permite determinar el grado de investigación que ha soportado cada uno de estos temas y definir qué aspectos han sido los que han acaparado la atención de la investigación a lo largo del tiempo.

Atendiendo a los datos proporcionados por los once grupos temáticos definidos, aquellos documentos que se centran en el estudio de uno o varios yacimientos son los mayoritarios, con 755 documentos, el 34,5\% sobre el total de la producción. Dentro de este grupo, y al margen de 27 documentos que se refieren a conjuntos que tienen representaciones de los dos estilos y que han sido contabilizados en los dos grupos, podríamos diferenciar entre aquellos trabajos dedicados al estudio de yacimientos con pinturas de estilo levantino de aquellos otros con representaciones de estilo esquemático. En este caso, las cifras indican un número sensiblemente más alto de investigaciones sobre conjuntos esquemáticos, con 417 trabajos, el 55,2\% del total del grupo temático, frente a los 337 referidos al estilo levantino, el 44,6\%.

La producción que hemos clasificado como 'General', constituye el segundo bloque de trabajos, con 579 (26,4\%). Se trata de un bloque integrado por aquellos estudios de carácter general sobre el arte rupestre o sobre un estilo concreto, en el que, a modo de obras de síntesis, se abordan la mayor parte de los temas de estudio del arte prehistórico, pero sin ceñirse de forma concreta a alguno de ellos porque no se contempla la realización de un análisis profundo ni exhaustivo de un aspecto concreto. Las referencias de cada uno de los ámbitos tratados en la mayoría de los casos son tan genéricas que aconsejan que se agrupen en un único bloque de estudios carácter general, ya que su inclusión en los diferentes apartados temáticos individualizados daría una imagen irreal de la investigación, puesto que la simple alusión a iconografía, técnica o cronología, por ejemplo, no los convierte en documentos paradigmáticos de la investigación de esos temas. Asimismo, por el alto porcentaje que significa dentro de la producción científica y por su distribución temporal nos parece un bloque de interés para conocer por donde ha discurrido una parte importante de la investigación. 
Los otros temas han sido tratados en menor medida. Los más analizados han sido la 'Cronología’ con 193 trabajos (8,8\%), la ‘Iconografía’ con 170 (7,7\%) y la ‘Divulgación’ con 112 documentos (5,1\%) (Tabla IV).

\begin{tabular}{lcr}
\hline Tema & Publicaciones & $\mathbf{\%}$ \\
\hline Yacimiento & 755 & 34,5 \\
\hline General & 579 & 26,4 \\
\hline Cronología & 193 & 8,8 \\
\hline Iconografía & 170 & 7,7 \\
\hline Divulgación & 112 & 5,1 \\
\hline Metodología & 93 & 4,2 \\
\hline Semiótica & 91 & 4,1 \\
\hline Conservación & 88 & 4,0 \\
\hline Historiografía & 58 & 2,6 \\
\hline Técnica & 32 & 1,4 \\
\hline Gestión & 15 & 0,6 \\
\hline Total & 2.186 & 100 \\
\hline
\end{tabular}

Tabla IV. Distribución de la producción por temáticas.

La evolución de estos temas a lo largo del periodo de investigación analizado ha sido desigual. Desde el principio, el grupo más numeroso de trabajos era el que tenía como tema central el estudio de yacimientos concretos, tanto levantinos como esquemáticos, mientras que el bloque de los documentos de temática general ocupaba la segunda posición. Ha sido en las dos últimas décadas cuando se ha invertido la situación de uno y otro, aunque con unos márgenes muy próximos. El resto de temas ha estado presente a lo largo del periodo 1907-2010 de forma muy modesta, con una presencia prácticamente testimonial en los primeros cincuenta años de la misma, a excepción de la 'Cronología', que entre 1950 y 1980 sí tuvo un incremento progresivo, relativamente próximo al de los dos grupos temáticos mayoritarios, pero que, a pesar de seguir teniendo un crecimiento continuo hasta la actualidad, finalmente se ha distanciado del volumen alcanzado por aquellos.

Hay que destacar como hecho significativo que ha sido durante la última década de investigación cuando muchos de los núcleos temáticos generan casi el $50 \%$ de su producción, porcentaje que incluso superan ampliamente en algún caso concreto. Se acercan a ese 50\% la ‘Iconografía’ con el 44,1\%, la 'Divulgación' con el 44,6\% y la 'Semiótica' con el 47,2\%, mientras que superan ese porcentaje la 'Historiografía’ con el 55,1\%, la 'Metodología’ con el 56,9\% y, llamativo, la 'Gestión', que desarrolla hasta el 86,6\% de su producción en estos últimos diez años de estudio. La 'Técnica’ también sitúa el 50\% de su producción en este periodo.

Entre los factores que explicarían este relevante aumento de la producción en estas áreas temáticas durante esta última década podríamos reseñar, como punto de inflexión, la declaración del arte rupestre del arco mediterráneo como patrimonio mundial. Ésta implica la realización por parte de las administraciones de un mayor esfuerzo por potenciar ámbitos de estudio hasta entonces poco desarrollados. El arte rupestre no es ya sólo un hecho arqueológico de cuyo estudio se ocupan los científicos, sino que adquiere una dimensión cultural, social y económica, como factor dinamizador en aquellas áreas en las que se inscribe, que obligan a la adopción de medidas muy heterogéneas que satisfagan esa demanda social. Ello hace que la investigación deba cubrir unos espacios que hasta entonces no parecían tan prioritarios como puedan ser los relativos a la conservación, valorando y discriminando los métodos y sistemas más adecuados, la divulgación, con vistas a acercar el fenómeno rupestre a la sociedad en general y no solo al ámbito restringido de los investigadores, lo que obliga a ejecutar nuevas prácticas de gestión, o la metodología de trabajo, con la aplicación de nuevas técnicas procedentes de otras ramas de la ciencia.

También influye una nueva concepción del arte prehistórico por parte de la propia investigación, que ha dejado de verlo como un hecho puramente estético para valorarlo, antes bien, como una faceta cultural más de unos grupos sociales determinados, que responde a unos fines muy alejados de lo estrictamente estético.

\subsubsection{Clasificación temática en el arte levantino.}

El panorama descrito para la pintura rupestre en conjunto encuentra correlación, en general, si el análisis lo hacemos de manera individualizada para cada estilo. Así, en la producción relativa al horizonte levantino, el bloque de 'Yacimientos' es también el mayoritario de forma clara a lo largo de todo el periodo de investigación, con un 43,4\% 
sobre el total de la producción sobre este estilo, aunque sobresale la década de 1981-1990 en la que se edita el 22,2\% de todo el grupo.

En cuanto al segundo bloque temático por número de documentos, el estilo levantino difiere de los datos globales comentados sobre los dos estilos conjuntamente. Si allí el segundo bloque era el dedicado a los estudios generales, aquí tiene a la 'Iconografía' como protagonista, que con 124 trabajos, supone el 15,9\% del conjunto de títulos sobre arte levantino. Su mayor desarrollo se produce desde los años setenta, si bien ha sido en la década de 2001-2010 cuando ha duplicado su número, con 51 documentos, el 41,1\% del grupo temático.

La tercera categoría es la de los estudios de carácter 'General'. Con un 13,7\% de la producción total sobre este estilo levantino, está presente desde los primeros trabajos a comienzos del siglo XX, si bien su volumen se incrementa significativamente desde los años setenta. De hecho, desde entonces y hasta la actualidad se edita el 81,3\% sobre el tema.

La cuarta unidad temática es la dedicada a la 'Cronología'. Con 84 trabajos, el 10,8\% de lo editado específicamente sobre arte levantino, su producción se estabiliza en torno a los 15-20 documentos por década desde los años sesenta, ya que con anterioridad su presencia es más bien escasa, solo 10 documentos, el 11,9\%.

Los otros temas tratados en el arte levantino muestran una correspondencia estrecha con los datos del análisis conjunto de ambos estilos. Por orden decreciente la producción se distribuye entre la 'Semiótica' (4,6\%), la 'Metodología’ (3,2\%), la 'Divulgación’ (2,5\%), la 'Conservación’ (1,8\%), la 'Historiografía’ (1,6\%), la 'Técnica' $(1,9 \%)$ y la 'Gestión’ (0,1\%). Sí debemos destacar el caso de la 'Semiótica', sobre la que hasta la década de los años noventa solo contábamos con cuatro trabajos, y que en estas dos últimas décadas ha irrumpido con fuerza como tema de estudio dentro del estilo levantino, duplicando incluso su producción de una década a otra, con 10 estudios editados entre 1991 y 2000, y 22 trabajos más entre 2001 y 2010.

Todos estos datos coinciden, con algún matiz, con los ofrecidos por el estudio bibliométrico realizado hace unos años sobre el arte rupestre levantino (Cruz et al., 1999). Aunque no hay una correspondencia exacta entre los núcleos temáticos definidos en cada trabajo, y obviando el bloque denominado en ese trabajo como 'Resto', muy heterogéneo y en el que se englobarían algunos de los temas que nosotros hemos individualizado, el tema con más publicaciones es el de los 'Hallazgos' con 285 documentos (54,8\%), seguido de la 'Iconografía', con 56 trabajos (11,1\%), el grupo de 'Conservación-Metodología’, con 49 (9,4\%) y la ‘Cronología’ con 38 publicaciones (7,3\%).

Si tenemos en cuenta que los autores del artículo no individualizan un grupo de obras generales y también que nosotros hemos tratado por separado la 'Conservación' y la 'Metodología', los datos relativos a los otros núcleos temáticos sí mantienen el orden decreciente en el número de publicaciones. La variación en los porcentajes se explicaría por la desigual cantidad de documentos analizados en cada estudio, los 776 manejados por nosotros frente a 521 documentos contabilizados entonces.

\subsubsection{Clasificación temática en la pintura rupestre esquemática.}

En la investigación de la pintura rupestre esquemática, el tema 'Yacimientos' es también el mayoritario desde un primer momento y con una notable diferencia sobre el resto de grupos temáticos. Con 417 trabajos, supone el 54,7\% del total de la producción sobre este estilo, con un especial desarrollo entre los años 1981 y 2000, cuando se publica el 55,8\% de toda la producción sobre el tema y el 30,5\% del total de la producción sobre pintura esquemática.

Sin embargo, a diferencia de lo que ocurría con el estilo levantino, el segundo tema más tratado es el 'General', con 188 documentos (24,6\%), mientras que la 'Cronología' con 59 (7,7\%) ocupa el tercer lugar. En ambos casos, ha sido a partir de los años setenta cuando la producción alcanza un notable desarrollo en comparación con las paupérrimas cifras de los años anteriores. Hasta entonces, en el grupo de 'General' tan solo contabilizábamos 11 documentos, el 5,8\% de todo el núcleo temático, mientras que sobre la 'Cronología' el panorama es aún más llamativo ya que hasta 1971 tan solo contábamos con dos publicaciones específicas, el 3,3\% de lo editado sobre el tema.

La 'Iconografía’ y la 'Semiótica' cuentan cada una de ellas con 29 publicaciones (3,8\%), mientras que el resto de temas muestran unos porcentajes muy modestos: la 'Metodología' tiene 13 publicaciones (1,7\%), la 'Divulgación’ y la ‘Conservación’ 8 trabajos cada una (1\%), la ‘Historiografía’ 6 estudios (0,7\%) y la ‘Técnica’ 4 documentos (0,5\%). La ‘Gestión’ no cuenta con ningún estudio específico referido a la pintura rupestre esquemática. 


\subsection{Distribución de la producción por lugar de publicación.}

De los 2186 documentos contabilizados, 1981 han sido editados en España (90,6\%), frente a los 205 que lo han sido en el extranjero $(9,4 \%)$. Ello denota la escasa presencia de los estudios sobre pintura rupestre pospaleolítica en publicaciones internacionales, ya sea como artículos incluidos en revistas científicas o, en su caso, como comunicaciones a congresos o monografías.

\subsubsection{Lugares de publicación en España.}

Zaragoza con 294 (13,4\%), Madrid con 292 (13,3\%), Valencia con 202 (9,2\%), Murcia con 198 (9\%), Barcelona con $153(6,9 \%)$ y Alicante con 104 (4,7\%) son las seis provincias con mayor número de documentos editados.

Por el contrario, otras 25 ciudades cuentan con menos de 10 trabajos editados, e incluso en otras seis se ha publicado un único documento.

El escaso número de yacimientos con pintura rupestre que conocemos en Zaragoza contrasta con el elevado número de publicaciones editadas, lo cual podría parecer hasta cierto punto paradójico. Sin embargo, hay varios factores que explicarían ese elevado número de documentos. La Secretaría de los Congresos Nacionales de Arqueología, responsable de la edición de las actas de 22 de las 26 ediciones celebradas, está vinculada al Seminario de Arqueología, Numismática y Epigrafía de la Universidad de Zaragoza. También editada por el propio Seminario de Arqueología de la Universidad de Zaragoza, la serie de las Monografías Arqueológicas ha tenido en el arte rupestre uno de los temas más publicitados. La razón de esta importante actividad de difusión por parte de la Universidad de Zaragoza la tiene la figura de A. Beltrán Martínez, uno de los principales investigadores del arte rupestre desde los años sesenta del siglo pasado, primero en su calidad de catedrático de Arqueología, Numismática y Epigrafía de la citada Universidad, luego como catedrático de Prehistoria en esta misma institución, y hasta su muerte como emérito de la misma.

Otros organismos públicos también han tenido especial protagonismo en la difusión de las investigaciones sobre arte rupestre. La Institución Fernando 'el Católico', dependiente de la Diputación de Zaragoza, edita la revista Caesaraugusta que, dedicada a la arqueología, la prehistoria y la historia antigua, ha recogido un grupo de 48 estudios sobre pintura rupestre pospaleolítica.

La creación de diversos parques culturales en torno al arte rupestre desde inicios de los años noventa, en concreto los del río Martín, el de Albarracín y el del río Vero, ha promovido el nacimiento de publicaciones periódicas que actúan como portavoces de dichos parques y que, lógicamente, han prestado especial atención a las investigaciones sobre arte rupestre. Es el caso de las revistas Cauce y del Boletín de Arte Rupestre de Aragón. Íntimamente relacionadas con los parques, también han sido numerosas las publicaciones monográficas editadas sobre otros tantos yacimientos, englobadas la mayor parte de ellas en la serie Parques Culturales de Aragón.

Entre 1985 y 1994 estuvo activa la serie Arqueología Aragonesa, dependiente del Departamento de Cultura y Educación de la Diputación General de Aragón, y entre 1982 y 1988 se publicó la revista Bajo Aragón, Prehistoria, editada por el Grupo Cultural Caspolino, dedicando ambas publicaciones especial atención a los trabajos sobre pintura rupestre prehistórica.

El alto número de trabajos editados en Madrid encuentra explicación, de una parte, en el centralismo que envuelve la investigación del arte rupestre, como es común al resto de la investigación arqueológica española en general, al menos durante los primeros cuarenta años de estudio, y de otra en la labor desarrollada a partir de entonces tanto por instituciones públicas como por entidades privadas.

Durante los primeros años de la investigación del arte rupestre, el protagonismo en los estudios lo ostentan, junto a algunos organismos catalanes, entidades de carácter estatal arraigadas en Madrid como la Comisión de Investigaciones Paleontológicas y Prehistóricas, dependiente del Museo de Ciencias Naturales, la Sociedad Española de Antropología, Etnografía y Prehistoria, la Sociedad Ibérica de Ciencias Naturales o la Sociedad Española de Historia Natural, responsables de gran parte de las publicaciones sobre arte rupestre hasta prácticamente la primera mitad del siglo pasado.

Posteriormente, se produce una descentralización en los estudios sobre arte rupestre, cuyo peso no recae ya en tan alto porcentaje sobre organismos estatales, que se ven sustituidos por los de carácter autonómico desde los años ochenta, aunque la labor de instituciones como el Instituto de Historia, dependiente del CSIC, responsable de revistas 
como el Archivo Español de Arqueología o Trabajos de Prehistoria, o la Asociación de Amigos de la Arqueología, que edita su boletín anual, entre otras entidades, mantendrán a Madrid a la vanguardia de las ciudades editoras de trabajos sobre el tema.

También tendrán un papel activo algunas universidades. Revistas como Espacio, Tiempo y Forma, editada por el Departamento de Prehistoria e Historia Antigua de la UNED, o los Cuadernos de Prehistoria y Arqueología, tutelados por el Departamento de Prehistoria de la Universidad Autónoma, dan cabida a un importante número de publicaciones.

En el ámbito privado debemos destacar la labor desarrollada por Zugarto Ediciones, S.A., responsable de la Revista de Arqueología, que hasta el año 2010 había publicado 45 trabajos sobre pintura rupestre pospaleolítica de los estilos levantino y esquemático, además de un número monográfico con nueve estudios más.

Aunque Valencia publica muy pronto, ya que en 1912 la Societat Lo Rat- Penat recoge en su Boletín el descubrimiento de la Cueva de Tortosilla en Ayora, que constituye el primer testimonio de arte levantino en la región, lo cierto es que hasta la década de los años noventa los trabajos editados no son muy numerosos, destacando tan sólo las publicaciones dependientes del Servicio de Investigación Prehistórica de la Diputación, bien a través de su revista Archivo de Prehistoria Levantina, o bien en su serie de Trabajos Varios del S.I.P. De hecho, hasta 1990 el número total de publicaciones con depósito legal en Valencia apenas era de 49, y de 82 hasta el año 2000, una cifra relativamente baja, sobre todo en comparación con los 202 títulos con que contamos en la actualidad. Ese impulso tan significativo, que ha supuesto que en estos últimos diez años Valencia haya editado el 59,4\% del total de su producción, se ha debido tanto a la continuidad de instituciones existentes desde antiguo, como el citado Servicio de Investigación Prehistórica, como a la incorporación al estudio del arte rupestre de otras instituciones como la Universidad de Valencia, a través del Departamento de Prehistoria y Arqueología y su revista Saguntum, o la Sección de Prehistoria y Arqueología de la Real Academia de Cultura Valenciana, editora ella sola de medio centenar de trabajos en sus series Arqueológica, Histórica y Popular, y organizadora, desde 1999, de anuales Seminarios de Estudio sobre Arte Prehistórico, primero en su sede de Gandía y desde 2007 en el Museo de la Valltorta en Tírig (Castellón).

También ha tenido un papel destacado en el estudio del arte rupestre y, con ello, en la edición de sus investigaciones el Instituto de Arte Rupestre, dependiente del Instituto Valenciano de Conservación y Restauración de Bienes Culturales de la Generalitat Valenciana.

Murcia tiene fechada su publicación más antigua en 1947, en una comunicación presentada al III Congreso Arqueológico del Sudeste de España celebrado en la ciudad ese mismo año, pero va a ser a partir de la década de los años ochenta cuando inicie una importante labor editorial de tal forma que ha sido en estos últimos tres decenios cuando ha publicado el 94,4\% de su producción.

En este impulso a la edición ha influido en gran manera la creación de una serie de revistas locales, vinculadas generalmente a museos arqueológicos municipales, como son las revistas Alquipir en Cehegín, Yakka en Yecla, Pleita en Jumilla o los Cuadernos de Arte Rupestre en Moratalla, y también por la potenciación en estos años de otras publicaciones que permanecían un tanto aletargadas, como es el caso de los Anales de Prehistoria y Arqueología de la Universidad de Murcia o de Verdolay, dependiente del Museo Arqueológico de Murcia. Sus publicaciones suponen el 29.1\% del total de la producción en Murcia.

A su vez, el desarrollo anual de unas Jornadas de Arqueología Regional, con continuidad entre 1989 y 2008, y la edición de sus actas de manera asociada a las Memorias de Arqueología, ha contribuido eficazmente a la publicación de aquellos trabajos realizados en esos años sobre el arte rupestre regional.

La celebración del XXIV Congreso Nacional de Arqueología en Cartagena en 1997 también supuso la edición de un importante grupo de estudios sobre arte rupestre ya que, con 18 comunicaciones, fue una de las ediciones de los congresos nacionales más prolíficas en este campo de estudio.

Barcelona comienza a editar muy pronto sobre pintura rupestre. De hecho, la indefinición que envuelve a la gestión de la investigación arqueológica en España durante las primeras décadas del siglo XX, concede especial protagonismo a asociaciones e instituciones de carácter local y regional que tienen unos ámbitos de estudio que superan ampliamente los puramente arqueológicos. En Cataluña son el Centre Excursionista de Catalunya, el Institut d'Estudis Catalans, o la Asociación Catalana de Antropología, Etnografía y Prehistoria, entre otros, quienes asumen este protagonismo. A investigadores vinculados a estas entidades se deben algunos de los primeros trabajos sobre pintura rupestre pospaleolítica, a veces en enconada rivalidad con organismos estatales, como la propia Comisión de Investigaciones 
Paleontológicas y Prehistóricas, con la que llega a repartirse áreas de estudio en el Barranco de la Valltorta, o extranjeros, como el propio Instituto de Paleontología Humana de París. En la primera década de investigación se publican cinco trabajos (3,2\%), aunque a partir de ese momento la producción se va estabilizando, con algún retroceso incluido, en cifras muy modestas hasta la década de los años sesenta, momento en que se produce un despegue en la edición de trabajos que se va a mantener hasta la actualidad sin grandes altibajos.

En Alicante nos encontramos con una situación muy próxima a la comentada de Murcia, más acusada si cabe puesto que si bien ha sido durante las tres últimas décadas cuando ha publicado el 96,1\% del total de su producción, hasta el 53,8\% de la misma se fecha en el periodo 2001-2010. Si hasta entonces se mantenía en un volumen de edición más bien modesto, la celebración del Congreso sobre Arte Rupestre en la España Mediterránea en 2005, a cargo del Instituto Alicantino de Cultura Juan Gil-Albert, de la Diputación de Alicante, ha revitalizado el interés por el estudio del arte rupestre, complementando la labor que desde los últimos años del pasado siglo XX y en la primera década del XXI vienen desarrollando otras instituciones como el Centro de Estudios Contestanos, responsable de la edición de la revista Alberri y de varias series monográficas dedicadas al tema, el Museo Arqueológico de Alcoy, con sus Recerques del Museu d'Alcoi, o la propia Universidad de Alicante que, desde el Departamento de Prehistoria y a través de la revista Lucentum, tiene una dedicación especial al estudio y la difusión de las investigaciones sobre el arte prehistórico.

También debemos destacar, por su particularidad, los casos de Castellón y de Salamanca, séptima y octava provincias, respectivamente, en las que más documentos sobre pintura rupestre pospaleolítica se han editado durante el periodo temporal analizado.

Castellón, que cuenta con 96 documentos editados, fecha muy pronto su primer trabajo, en 1924, en un estudio sobre Els problemas arqueòlogics de la Provincia de Castelló firmado por P. Bosch y publicado en el Boletín de la Sociedad Castellonense de Cultura. Será precisamente esta institución de estudios locales la que asuma casi exclusivamente la tarea de estudio y difusión del arte rupestre. De hecho, en su Boletín se han publicado 28 trabajos, la mayoría de ellos vinculados a la figura de Juan B. Porcar, pintor y estudioso del arte rupestre del Barranco de la Valltorta, lo que supone el 29,1\% de lo producido en Castellón.

Desde la década de los setenta el protagonismo lo va asumir el Servicio de Arqueología de la Diputación de Castellón, que a través de los Cuadernos de Prehistoria y Arqueología Castellonense va a editar otros 39 trabajos, el 40,6\% del total. La Universidad Jaime I también ha recogido varios estudios en su revista Millars, en concreto el 6,2\% de lo publicado en la provincia.

Si en el caso de Castellón son dos las instituciones que acaparan prácticamente el 69,7\% de las publicaciones, cuando analizamos la producción de Salamanca, que comienza en 1950, solo podemos citar, con alguna excepción, la labor desarrollada por la Cátedra de Arqueología de la Universidad de Salamanca y su revista Zéphyrus que, con 84 trabajos, acapara el 91,3\% de todo lo editado en la provincia. En esta implicación en la edición de estudios sobre arte rupestre tiene gran responsabilidad la figura de F. Jordá Cerdá, Catedrático de Arqueología de la Universidad de Salamanca y una de las figuras más relevantes en el estudio del arte rupestre peninsular hasta comienzos de la década de los años noventa.

También tuvo especial incidencia la celebración en 1982 del I Coloquio Internacional sobre Arte Esquemático, promovido también por la Universidad de Salamanca y cuyas actas fueron publicadas en la propia revista Zéphyrus.

\subsubsection{Lugares de publicación en el extranjero.}

De los 205 documentos editados fuera de España con los que hemos trabajado, de veinte de ellos no hemos podido conocer el lugar de edición y en dos casos desconocemos la fecha de edición. Estos 205 documentos suponen el 9,4\% del total de la producción y se reparten en 62 ciudades diferentes y por diferentes décadas (Figura 2). París es la que reúne un mayor número de trabajos, 36 (17,5\%), lo que se explica por el protagonismo que durante los primeros años de investigación del arte rupestre español tuvo el Instituto de Paleontología Humana de París y la revista L’Anthropologie, dependiente de este organismo. Esta publicación se convirtió en el vehículo de difusión de los estudios realizados por investigadores como H. Breuil, E. Cartailhac o H. Obermaier, entre otros, hasta el punto de que, de los 20 artículos recogidos en la revista, 14 son anteriores a 1937 y están firmados por H. Breuil en su mayor parte, por H. Obermaier, o por los dos en coautoría, aunque eventualmente acompañen su firma otras colaboraciones puntuales. En los años siguientes, L’Anthropologie sigue prestando atención a la divulgación del arte rupestre peninsular con algunos otros trabajos. Por su parte, en los años cincuenta y sesenta también se despierta el interés de la 
Société Préhistorique Française que, en su Bulletin anual, recoge hasta seis estudios, bien sobre el arte rupestre español en general o también sobre algún yacimiento en particular.

Tras París, hay un grupo de cinco ciudades que cuenta con ocho documentos editados en cada una de ellas sobre pintura rupestre pospaleolítica peninsular, lo que significa en cada caso el 3,9\% de la producción total publicada en el extranjero. Se trata de Leipzig (Alemania), Chicago (Estados Unidos), Oporto (Portugal), Tarascon sur Ariège (Francia) y Tomar (Portugal).

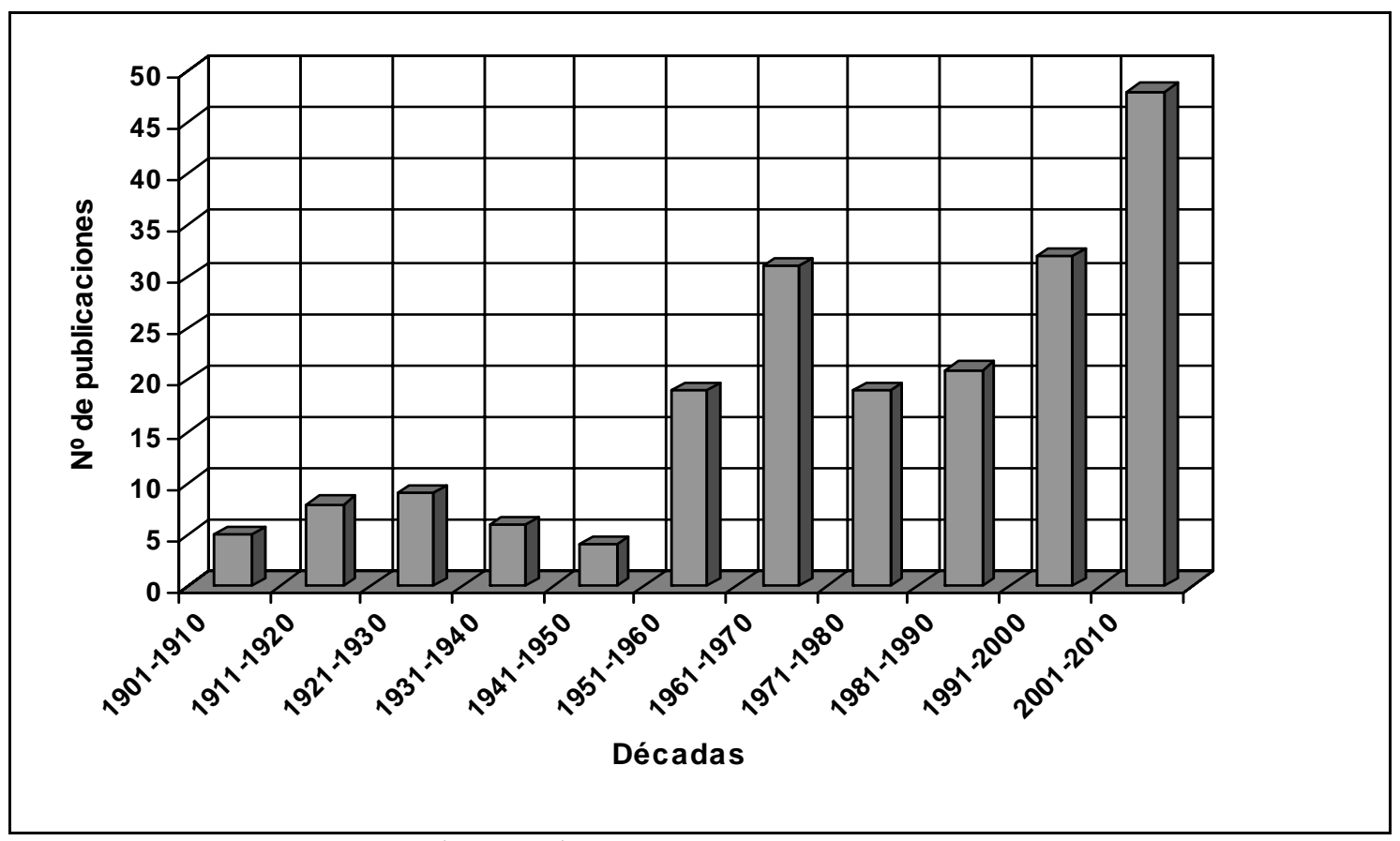

Figura 2. Distribución cronológica de los documentos publicados fuera de España.

En el caso de Leipzig, cuyas publicaciones sobre pintura pospaleolítica se remontan a fechas tan tempranas en la investigación como la de 1921, los estudios están vinculados a la revista Ipek y a los autores extranjeros que monopolizan gran parte de la investigación en los primeros años, como son H. Breuil, H. Obermaier o H. Kühn, a los que ya en una etapa más moderna, en los años setenta, se les suman otros como A. Beltrán o M. Almagro. En Chicago, los ocho trabajos se deben a la iniciativa de la Wenner-Gren Foundation for Anthropological Research, que promueve en 1960 la celebración en Wartenstein del Symposium on Rock Art of Western Mediterranean and Sahara. En Oporto, siete de las ocho publicaciones están también vinculadas estrechamente a la celebración de congresos nacionales o peninsulares de arqueología. En concreto, cinco de ellas se presentan en el III Congresso de Arqueologia Peninsular celebrado en el año 2000 y un artículo recogido en la revista Journal of Iberian Archaeology. En Tarascon sur Ariége, el interés de la Société Préhistorique de l’Ariége por el arte rupestre español llevará a publicar varios artículos en su Bulletin, sobre todo en la década de los sesenta. Por último, el Centro de Prehistoria del Instituto Politécnico de Tomar editará los ocho artículos en sendos números de su revista Arkeos.

En Oxford se han editado seis documentos, el primero fechado ya en 1929. Destaca el interés de la British Archaeological Reports por el arte levantino en particular, al que ha dedicado dos números de sus BAR International Series.

Aunque en la década de los años cincuenta la edición de trabajos en el extranjero aumenta de forma notoria respecto a periodos anteriores, a partir de este momento la producción se estabiliza en torno a los 20-30 trabajos por década, con leves fluctuaciones, aunque siempre dentro de estas cifras modestas. Ha sido en la última década de investigación cuando el número de trabajos ha aumentado hasta el punto de casi duplicar la cifra más alta de etapas anteriores. Son 48 documentos, que suponen el 23,4\% de toda la producción publicada fuera, lo que podría ser interpretado como un cambio de tendencia entre los autores que, aunque todavía en una cantidad muy baja en relación al volumen total de documentos generados, muestran un mayor interés por publicar fuera de España.

En cuanto a la tipología documental de los 205 documentos publicados en el extranjero, 123 son artículos (60\%), 44 son comunicaciones en congresos (21,4\%), 15 son capítulos de obras colectivas (7,3\%), 14 son monografías (6,8\%) 
y 8 son notas (3,9\%). También hay que destacar la lectura de una tesina de licenciatura en la École de Hautes Études en Sciences Sociales de Toulouse, a cargo de Ph. Haumeau, investigador francés que colabora con el Museo Provincial de Huesca en el estudio del arte rupestre oscense.

Este, aparente, escaso interés por parte de los autores españoles por superar las fronteras nacionales y divulgar sus investigaciones en foros internacionales, ya sea en revistas o en seminarios y congresos, parece común a otras materias arqueológicas, si bien la disparidad entre los porcentajes no es tan acusada como se verifica en nuestro examen. Así, en el estudio efectuado sobre las publicaciones referidas a los materiales cerámicos arqueológicos en España, de los 223 documentos computados, 45 han sido editados en el extranjero, el 20,4\% (García Heras, 1997). De éstos, el 68,8\% se incluye en las actas de congresos internacionales y tan sólo un $20 \%$ son artículos de revistas. También hay cuatro monografías (8,8\%), e incluso una tesis doctoral $(2,2 \%)$ ha sido defendida en una universidad extranjera.

\section{CONCLUSIONES.}

El objeto de estudio ha sido el análisis de la producción científica sobre la pintura rupestre pospaleolítica de los estilos levantino y esquemático, si bien, inicialmente se podría haber planteado la posibilidad de ampliar el tema de investigación a la producción referida a todo el arte pospaleolítico, pero ello planteaba inconvenientes, de índole muy diversa, que desaconsejaban la tarea. Una dificultad no menor, es la indefinición de los límites de lo que se entiende por 'arte pospaleolítico', sobre todo en lo que se refiere a su frontera más antigua. Así, la imprecisión que envuelve a muchos de los materiales, tanto parietales como muebles, que se adscriben unas veces a contextos finipaleolíticos, otras a fechas ya epipaleolíticas, impiden delimitar objetivamente lo que es o no pospaleolítico en sentido estricto, y con ello fijar la propia producción que sería objeto de estudio, que sí debe estar bien determinada. A la vez, la variedad de técnicas gráficas, soportes e incluso metodología de estudio del grafismo más reciente, desarrollado en espacios tan variados como son los parietales rupestres, los cerámicos, los pétreos de cantos y placas, o los propios de contextos megalíticos, así como el desarrollo de los mismos en marcos cronológicos variados que llegan hasta la edad de los metales, tampoco contribuyen a homogeneizar la producción científica. Por el contrario, consideramos que todas estas indecisiones han quedado minimizadas al centrar el trabajo en la pintura rupestre levantina y esquemática por cuanto, a la homogeneidad de soporte y técnica, se suma también la palpable correlación existente entre ambos horizontes gráficos en lo que se refiere a su investigación, que ha ido de la mano desde los inicios de la misma; ya que ésta ha sido protagonizada en un alto porcentaje por los mismos investigadores y porque su estudio comparte una misma metodología de trabajo. Más allá de discusiones académicas sobre variaciones estilísticas, sobre adscripciones cronológicas y culturales, o sobre cuestiones semánticas, la pintura rupestre pospaleolítica levantina y esquemática sí constituye un cuerpo temático bien delimitable, lo que posibilita a su vez que la producción científica vinculada a ella haya sido perfectamente cuantificable.

Y aunque la producción total analizada, integrada por 2186 documentos, no es excesivamente elevada dado el amplio espacio temporal durante el que se genera (1907-2010) y la media de publicaciones por año es baja, de apenas 21,01 trabajos/año, sí se advierte un notable incremento de la producción en los últimos cincuenta años, con tasas de crecimiento por encima del 5\% e, incluso, del $8 \%$ en la década de los años ochenta. Este incremento continuo en los últimos cincuenta años de investigación es el que nos permite afirmar que la producción bibliográfica sobre la pintura rupestre pospaleolítica en España se ajusta a un modelo de crecimiento exponencial, seña de identidad de una disciplina científica moderna. Sin embargo, los resultados obtenidos en nuestro análisis ponen de manifiesto la existencia de una serie de particularidades en la investigación que nos llevan a hacer unas consideraciones finales que, en nuestra opinión, pueden marcar parte del futuro de la misma.

Es previsible que la producción científica sobre la materia siga mostrando tasas de crecimiento positivo en los próximos años, aunque en términos absolutos dicha producción no tenga que ser forzosamente elevada dadas las particularidades de la propia materia objeto de estudio. A saber, su fuerte componente local y, al mismo tiempo, el marcado grado de especialización dentro de la prehistoria y la arqueología.

En todo caso, aunque el español es la segunda o tercera lengua más hablada en el mundo, sería necesaria una mayor internacionalización de la investigación de la pintura rupestre pospaleolítica española. El hecho de que el 88.1\% de los documentos publicados estén escritos en castellano, a lo que se une que el catalán sea el segundo idioma más empleado, indica implícitamente un déficit de internacionalización de la propia investigación, que se ve acentuada aún más si consideramos también que tan solo el 9,4\% de la producción se ha editado fuera de España. Y en esta realidad han influido factores muy diversos de entre los que debemos destacar el subrayado localismo en que se ha visto envuelto el estudio del arte pospaleolítico español, más acentuado en el caso del arte levantino, y la casi nula visibilidad de las publicaciones españolas en los repertorios bibliográficos internacionales. 
La idea de que el arte levantino español es un fenómeno local, idea arraigada, con puntuales excepciones, desde los primeros momentos de su estudio y que arrastraba consigo también a la pintura esquemática, favorecía entre los autores un, aparente al menos, estado de autocomplacencia en el que parece que bastaba con la simple edición de sus investigaciones en publicaciones nacionales, sin importar demasiado el alcance y la visibilidad que pudieran tener éstas. Da la impresión de que no ha existido ningún incentivo para publicar fuera de España, al margen de la incidencia que hayan podido tener en ello eventuales limitaciones como puedan ser las idiomáticas.

Sin embargo, la concepción actual es que el arte rupestre es un fenómeno universal, presente en los cinco continentes y en los más variados entornos culturales y cronológicos. Más allá de las particularidades regionales, el arte rupestre es un hecho antropológico colectivo y en este contexto, la participación e intercambio de ideas de los investigadores españoles en foros internacionales, la edición de sus trabajos en publicaciones extranjeras y la colaboración internacional redundarán positivamente en la investigación del arte rupestre prehistórico español.

Al mismo tiempo, las publicaciones españolas deben hacerse presentes en las bases de datos internacionales, para lo cual es necesario que hagan un esfuerzo por cumplir con los requisitos de calidad exigidos. Es verdad que en estos últimos años las entidades editoras de algunas de las más importantes revistas españolas vinculadas a la prehistoria y la arqueología han realizado una destacable labor de revisión y mejora en pos de conseguir esa calidad que permita su difusión en el exterior. Sin embargo, la realidad es que a día de hoy la presencia de las revistas españolas en esas bases de datos internacionales y, por ende, en los citations index de referencia es prácticamente nula como ya señalaban García y Román (1998) y sigue siéndolo en la actualidad. Sin duda, la proyección de las publicaciones en el exterior y, con ello, de los trabajos de los investigadores nacionales sobre el arte rupestre español, contribuirá poderosamente a la internacionalización de éste, al tiempo que servirá de reclamo para que investigadores extranjeros se interesen también por él.

Una de las razones, muy negativas en nuestra opinión, que ha contribuido a este hecho es el rechazo de algunas publicaciones científicas españolas a aceptar originales que no estén redactados en español, lo que constituye un freno importante a las eventuales aportaciones que pudieran hacer investigadores foráneos. En un análisis efectuado en 2003 sobre las 1031 revistas españolas contabilizadas en las áreas de las Ciencias Sociales y las Humanidades indicaba que el 70,2\% de ellas sólo publicaba en idioma español, porcentaje que asciende hasta el 74\% si consideramos aquellas revistas que junto al castellano sólo aceptan los otros idiomas oficiales del Estado (Osca y Mateo, 2003). Si bien, se aprecia un cambio de tendencia puesto que revistas del área como Saguntum, Trabajos de Prehistoria, Zephyrus o Pyrenae están aceptando en los últimos años trabajos en italiano, francés e inglés.

El bajo factor de impacto que tienen en general las revistas nacionales y, sobre todo, su escasa presencia en las bases de datos internacionales, tampoco ayuda a la proyección en el extranjero de las investigaciones publicadas por autores españoles en estas revistas españolas y, a la vez, para la presencia de autores foráneos en las mismas. El último dato que conocemos del índice de impacto de las revistas españolas de Ciencias Sociales y Humanidades $<$ http://epuc.cchs.csic.es/resh/>, correspondiente al periodo 2005-2009, indica que Brigantium es la revista que tiene el índice más alto, con 1500, seguida de Trabajos de Prehistoria con 1131 y Spal. Revista de Prehistoria y Arqueología, con 1059. El resto de las 84 publicaciones analizadas sobre arqueología y prehistoria tiene un índice de impacto por debajo de 1.

La pobre proyección de las revistas españolas en el extranjero encuentra buen reflejo en la prácticamente nula presencia de éstas en la base de datos del Institute of Scientific Information (ISI), que a pesar de los sesgos de los que adolece, sobre todo idiomáticos y geográficos (Seglen, 1997; Bordons, 1999; Garfield, 1999; Diego, 2008) y de las limitaciones derivadas del propio procedimiento de obtención del factor de impacto (Buela-Casal, 2003), sigue siendo la referencia más aceptada para evaluar la calidad de las publicaciones y, sobre todo, su grado de internacionalización. De hecho, se podría decir que lo que no recogen las bases de datos del ISI no existe en el ámbito internacional. Del conjunto de revistas españolas del área de la arqueología y la prehistoria tan sólo una revista está indexada en la plataforma Web of Knowledge de Thomson Reuters ${ }^{\mathrm{TM}}$, Trabajos de Prehistoria, siendo únicamente 12 los trabajos reseñados sobre la pintura rupestre pospaleolítica peninsular en el momento en el que hicimos la última consulta.

Asimismo, creemos que la universidad quizás debería prestar mayor atención al estudio del arte prehistórico en general. El reducido número de tesis doctorales y de memorias de licenciatura elaboradas que hemos sido capaces de localizar en el extenso periodo de 104 años analizados, apenas supone el 1,7\% de la producción.

Los trabajos de carácter general sobre la pintura rupestre pospaleolítica tienen un peso importante en la producción, con un 26,4\% de lo publicado, y una presencia destacada a lo largo de todo el periodo temporal de 
análisis. Dado que la concepción actual del arte prehistórico es que se trata de una realidad muy compleja y con múltiples caras, es necesario en nuestra opinión la especialización a la hora de abordar el estudio de cada una de esas facetas y potenciar la edición de esos estudios técnicos, en los que intervendrán profesionales procedentes de otros ámbitos de la ciencia. La cronología o las cuestiones de técnica, por ejemplo, ya no se determinan sólo por el criterio de los prehistoriadores en función de aspectos iconográficos, sino que es preciso contar con la participación de especialistas en la aplicación de métodos físico-químicos de análisis del pigmento y de datación absoluta, por ejemplo. Es cierto que durante los últimos años hemos asistido a un despegue de este tipo de estudios pero, como ha quedado reflejado, los porcentajes siguen siendo muy pobres, todos ellos muy por debajo aún del 10\%, en el contexto de la producción total. Creemos que una línea futura de trabajo debe ir por la realización y publicación de este tipo de trabajos específicos, elaborados por equipos interdisciplinares de trabajo.

\section{BIBLIOGRAFÍA.}

ACOSTA MARTÍNEZ, P. La pintura rupestre esquemática en España. Facultad de Filosofía y Letras, Salamanca, Salamanca. Memorias del Seminario de Prehistoria y Arqueología, 1968, p. 250.

AGULLÓ MARTÍNEZ, A. Estudio bibliométrico de las publicaciones médicas españolas analizadas en el Índice Médico Español (1989-1991). Valencia: Universidad de Valencia, 1998.

ALCAÍN, M.D. Aspectos métricos de la información científica. Ciencias de la Información. La Habana, 1991.

ALEIXANDRE BENAVENT, R. y PORCEL TORRENS, A. El factor de impacto y los cómputos de citas en la evaluación de la actividad científicas y las revistas médicas. Trastornos Adictivos, 2000, vol. 1, nº 4, p. 164-171.

ARMADA, X.L. Indicadores bibliométricos, visibilidad y calidad de revistas científicas: en torno a Revista d'Arqueologia de Ponent. Revista d'Arqueologia de Ponent, 2009, vol. 19, p. 7-28.

BORDONS, M. y ZULUETA, M. ${ }^{a} A$. Evaluación de la actividad científica a través de los indicadores bibliométricos. Revista Española de Cardiología, 1999, vol. 52, p. 790-800.

Buela-Casal, G. Evaluación de la calidad de los artículos y de las revistas científicas: propuesta del factor de impacto ponderado y de un índice de calidad. Psicothema, 2003, vol. 5, nº1, p. 23-35.

CORDERO RUIZ, T. et al. La arqueometría de materiales cerámicos: una evaluación de la experiencia andaluza. Trabajos de Prehistoria, 2006, vol. 63, nº 1, p. 9-35.

CRESPO ORTIZ DE ZÁRATE, S. La aportación historiográfica de Hispania Antiqva a la Historia de la Antigüedad (1971-1995). Hispania Antiqva, 1995, vol. 19, p. 397-425.

CRUELLS, W. Aproximació bibliomètrica i indexs de Cota Zero (1985-1995). Cota Zero, 1995, vol. 11, p. $100-122$.

CRUZ BERROCAL, M.; GOYTRE SAMANIEGO, J.; LEAL VALLADARES, J.G. y LÓPEZ DOMÍNGUEZ, M. Crítica al estudio del arte rupestre levantino desde una perspectiva bibliométrica. Trabajos de Prehistoria, 1999, vol. 56, $\mathrm{n}^{\mathrm{0}} 1$, p. 53-75.

DIEGO CAMPS, M.D. Limitaciones de los indicadores bibliométricos en la evaluación de la actividad científica biomédica. Colombia Médica, 2008, vol. 39, nº 1, p. 74-79.

GARCÍA HERAS, M. Estudio bibliométrico de los trabajos de caracterización sobre materiales cerámicos arqueológicos en España: una valoración. Revista d'Arqueologia de Ponent, 1997, vol. 7, 129-150.

GARCÍA MARÍN, A. et al. ¿Nos pasamos de la raya?: la frontera hispano-portuguesa a través de las publicaciones de Prehistoria y Protohistoria. Trabajos de Prehistoria, 1997, vol. 54, nº 1, p. 35-56.

GARCÍA MARÍN, A. y ROMÁN ROMÁN, A. Las publicaciones periódicas de Historia Antigua, Prehistoria y Arqueología: difusión internacional. Trabajos de Prehistoria, 1998, vol. 55, nº 1, p. 139-146.

GARCÍA DEL TORO, M.A.; GARCÍA ABOLLÓ, J.L.; JUÁREZ PÉREZ, M. y LÓPEZ GUERAO, M.A. Estudio bibliométrico de la revista Archivo Español de Arqueología: foro nacional de investigación arqueológica. XXIV Congreso Nacional de Arqueología (Cartagena, 1997), 1999, vol. 5, p. 329-338.

GARFIELD, E. Journal impact factor: a brief review. Canadian Medical Association Journal, 1999, vol. 161, p. 979980.

GUITIÁN CASTROMIL, J. y DE LA PEÑA SANTOS, A. Grabados en la memoria. Arte rupestre del noroeste: reasignaciones significativas y pervivencia icónica. Cuadernos de Arte Rupestre, 2007, vol. 4, p. 353-372.

LASCURAIN, M.L., López-López, P. y González-Uceda, L. Psicología y bibliometría en España. Revista General de Información y Documentación, 1997, vol. 7, p. 95-107.

LÓPEZ PIÑERO, J.M. El análisis estadístico y sociométrico de la literatura científica. Valencia: Centro de documentación e Informática Médica, 1972.

MALTRÁS BARBA, B. Los indicadores bibliométricos. Fundamentos y aplicación al análisis de la ciencia. Gijón: Trea, 2003.

MATEO SAURA, M.A. Arte naturalista en Murcia. Aspectos socioeconómicos y etnográficos. Murcia: Universidad de Murcia, 1992. 
MIGUEL DASIT, A. Estudio bibliométrico de las publicaciones españolas sobre diagnóstico por la imagen (19941998). Valencia: Universidad de Valencia, 2003.

MONTORO, L. y CARBONELL, E. La comunicación científica en psicología: producción y diseminación de la Información. Tratado de psicología general. 1. Historia, teoría y método. Madrid: Alhambra, 1989.

MORAVCSIK, M.J. ¿Cómo evaluar a la ciencia y a los científicos? Revista Española de Documentación Científica, 1989, vol. 12, nº 3, p. 313-325.

MORA, G. Archivo Español de Arqueología. Notas para una historia de la revista. Archivo Español de Arqueología, 2002, vol. 15, p. 5-20.

MOYA ANEGÓN, F. Indicadores bibliométricos de la actividad científica española 2008. Madrid: CSICUniversidad de Granada-SCImago Research Group, 2010. [en línea]. Disponible en: $<$ http://www.cchs.csic.es/node/276443> [Consulta: 11 de agosto de 2013].

OSCA LLUCH, J. y MATEO MARQUINA, M. ${ }^{\mathrm{a}}$ E. Difusión de las revistas españolas de ciencias sociales y humanidades. Acercamiento bibliométrico. Revista General de Información y Documentación, 2003, vol. 13, n 1 , p. 115-132.

PRICE, D. J. de S. Science since Babylon. New Haven: Yale University Press, 1961.

PRICE, D. J. de S. Some remarks on elitism in information and the invisible college phenomenon in science. Journal of the American Society for Information Science, 1971, vol. 22, $\mathrm{n}^{\circ}$ 2, p. 74-75.

PRICE, D. J. de S. Towards a model for science indicators. In: ELKANA, Y. et al. (Eds.), Toward a metric of science: The advent of science indicators. New York: John Wiley, 1978, p. 69-95.

PRITCHARD, A. Statistical Bibliography or Bibliometrics? Journal of Documentation, 1969, vol. 25, nº 4, p. 348349.

RODRÍGUEZ ALCALDE, A.L. Análisis bibliométrico de Trabajos de Prehistoria: un chequeo a la prehistoria española de las tres últimas décadas. Trabajos de Prehistoria, 1993, vol. 50, p. 11-37.

RODRÍGUEZ ALCALDE, A.L.; SÁNCHEZ NISTAL, J.M.; MARTÍNEZ NAVARRETE, M. I. y SAN MILLÁN BUJANDA, M. ${ }^{\mathrm{a} J}$. Análisis bibliométrico de las revistas españolas de prehistoria y arqueología en los últimos diez años. Trabajos de Prehistoria, 1996, vol. 53, p. 37-58.

RODRÍGUEZ ALCALDE, A.L.; SÁNCHEZ NISTAL, J.M. y MARTÍNEZ NAVARRETE, M. ${ }^{\mathrm{I} I . ~ E l ~ a n a ́ l i s i s ~}$ bibliométrico como aportación a la historiografía. Las citas en prehistoria y Arqueología. Málaga: Ediciones de la Diputación de Málaga, 1997.

RODRÍGUEZ YUNTA, L. y ABEJÓN PEÑA, T. El análisis bibliométrico de la producción española en Ciencias Sociales y Humanas ¿Contamos con las fuentes necesarias? Revista Española de Documentación Científica, 2010, vol. 33, n⿳0 1 , p. 145-161.

ROVIRA LLORENS, S. Estudio bibliométrico del Boletín de la Asociación de Amigos de la Arqueología. Boletín de la Asociación de Amigos de la Arqueología, 1994, vol. 34, p. 57-65.

RUBIO LINIERS, M. ${ }^{\mathrm{a} C}$. Bibliometría y Ciencias Sociales, 1999 [en línea]. Disponible en: $<$ http:77clio.rediris.es/articulos/Bibliometría.htm> [Consulta: 3 de abril de 2013].

SANCHO, R. Indicadores bibliométricos utilizados en la evaluación de la ciencia y la tecnología. Revisión bibliográfica. Revista Española de Documentación Científica, 1990, vol. 13, nº 3-4, p. 842-865.

SEGLEN, P.O. Why the impact factor of journals should not be used for evaluating research. British Medical Journal, 1997, vol. 314, p. 498-502.

TERRADA, M.L. España en el panorama internacional de las publicaciones médicas. Medicina Española, 1971, vol. 66, p. 191-198.

TERRADA, M.L. El «impacto» internacional de la literatura médica española contemporánea: índice de visibilidad de Platz. Medicina Española, 1973, vol. 70, p. 239-244.

TORTOSA, F. Las redes de revistas psicológicas como instrumento historiográfico. En: Estudios de historia de la psicología. Teoría y métodos de investigación. Salamanca: ICE, Universidad de Salamanca, 1985. 